Review Article

\title{
Recent Trends in Pharmacological Activity of Alkaloids in Animal Colitis: Potential Use for Inflammatory Bowel Disease
}

\author{
Ana Cristina Alves de Almeida, ${ }^{1}$ Felipe Meira de-Faria, ${ }^{1}$ \\ Ricardo José Dunder, ${ }^{2}$ Luis Paulo Bognoni Manzo, ${ }^{1}$ \\ Alba Regina Monteiro Souza-Brito, ${ }^{1}$ and Anderson Luiz-Ferreira ${ }^{3}$ \\ ${ }^{1}$ Institute of Biology, Department of Structural and Functional Biology, University of Campinas, Campinas, SP, Brazil \\ ${ }^{2}$ Faculty of Medical Sciences, Department of Pharmacology, University of Campinas, Campinas, SP, Brazil \\ ${ }^{3}$ Institute of Biotechnology, Department of Biological Sciences, Federal University of Goiás, Catalão, GO, Brazil
}

Correspondence should be addressed to Ana Cristina Alves de Almeida; aninhadabio@gmail.com

Received 6 September 2016; Revised 30 October 2016; Accepted 24 November 2016; Published 9 January 2017

Academic Editor: Caigan Du

Copyright (C) 2017 Ana Cristina Alves de Almeida et al. This is an open access article distributed under the Creative Commons Attribution License, which permits unrestricted use, distribution, and reproduction in any medium, provided the original work is properly cited.

\begin{abstract}
Inflammatory bowel disease (IBD) is a chronic and disrupted inflammation of the gastrointestinal tract. IBD have two main conditions, Crohn's disease and ulcerative colitis, and have been extensively investigated in recent years. Antibiotics derived from salicylates, steroids, immunosuppressors, and anti-TNF therapy are part of the therapeutic arsenal for IBD. However, very often patients stop responding to treatments over the time. In this context, searching for alternative agents is crucial for IBD clinical management. Natural products derived from medicinal plants are an interesting therapeutic alternative, since several studies have proven effective treatments in animal models of intestinal inflammation. Several naturally occurring compounds are potent antioxidants, both as free radical scavengers and as modulators of antioxidant enzymes expression and activity. A number of natural compounds have also been proved to inhibit the release of proinflammatory cytokines, decreasing the activation of nuclear factor $\kappa \mathrm{B}(\mathrm{NF}-\kappa \mathrm{B})$, which is important to the inflammatory response in IBD. The alkaloids are substances of a very diverse class of plant secondary metabolites; an extensive list of biological activities has been attributed to alkaloids, such as being anticholinergic, antitumor, diuretic, antiviral, antihypertensive, antiulcer, analgesic, and anti-inflammatory. In the present work, studies on the pharmacological activity of alkaloids in experimental models of IBD were reviewed.
\end{abstract}

\section{Introduction}

Inflammatory bowel disease (IBD) is a chronic inflammatory disorder in the gastrointestinal tract and primarily includes two forms, ulcerative colitis (UC) and Crohn's disease (CD) [1]. UC is characterized by an inflammatory response with edema, ulceration and bleeding, and morphological changes along with the intestine mucosae, involving infiltration of polymorphonuclear cells (PMN), abscesses formation in mucosal crypts, and glands distortion. These changes are concentrated in the mucosa and restricted to the colon and rectum [2]. CD can affect any portion of the gastrointestinal tract, disturbing mainly the submucosa, but may be transmural and exceed the serosa, creating fistulas [3]. Etiology of
IBD is complex and involves environmental factors, genetic factors, and an exacerbated immune response to commensal bacteria [4-6].

IBD was initially recognized as a health problem of developed countries; however, in a recent review, Molodecky and collaborators [7] have also reported increasing incidence and prevalence of IBD in developing countries, probably due to changes in lifestyles of these populations [8]

The therapy of IBD presents lack of effectiveness, high costs, and numerous side effects $[9,10]$. Although antiTNF $\alpha$ therapy revolutionized IBD clinical management, the number of reports showing loss of response in patients have been increasing. Moreover, almost one-third of IBD cases have not improved after anti-TNF $\alpha$ therapy [11]. 
Thus, the search for new alternative for the IBD therapy is still sine qua non.

For a century, natural products have been in the vanguard of drug discovery research, but, after the advent of automated high throughput screening (HTS) programs, the use of natural products in drug discovery in pharmaceutical industry declined [12]. However, natural products still continue to contribute to the drug development for cancer, infectious (bacterial, fungal, parasitic, and viral), immunological, cardiovascular, neurological, inflammatory, and related diseases $[13,14]$. There is an increase in the number of IBD patients using complementary herbal therapies and many experimental studies and clinical trials present beneficial effect of vegetal extracts, fractions, or compounds [15].

In this work, we made a review in the studies on the effects of alkaloids, a class of plant compounds with several biological activities reported, in experimental intestinal inflammatory injury.

\section{Alkaloids}

The definition of the term alkaloid is not simple, but, in general, alkaloids are a group of natural nitrogen-containing basic compounds with low molecular weight, synthetized from amino acids and biologically active [16]. Alkaloids are a diverse group of compounds found in bacteria, fungi, plants, and animals [17]. There are three types of alkaloids: true alkaloids, protoalkaloids, and pseudoalkaloids. True alkaloids have a heterocyclic ring with nitrogen, while, in the protoalkaloids, the $\mathrm{N}$ atom derived from amino acids is not part of heterocyclic ring. Pseudoalkaloids are not originated from amino acids, including terpene-like, purinelike, and steroid-like alkaloids. The major groups of alkaloids are summarized in Figure 1.

The first alkaloids for medicinal use were isolated at the beginning of 19th century, by Derosne (opium salt, narcotine) and Sertürner (principium somniferum, morphine). The chemical identification of morphine was carried in 1923 , by Robinson and Gulland $[18,19]$. So far, there are more than 20000 alkaloids identified and a number of them have been placed an important role in clinical practice [20]. They present numerous biological activities such as being emetic, anticholinergic, antitumor, diuretic, sympathomimetic, antiviral, antihypertensive, analgesic, antidepressant, muscle relaxant, anti-inflammatory, antimicrobial, and antiulcer $[21,22]$. The alkaloids have proton-accepting nitrogen atom and one or more proton-donating amine hydrogen atoms, which form hydrogen bonds with proteins, enzymes, and receptors. Furthermore, they, generally, have functional groups such as phenolic hydroxyl. The later might explain the exceptional bioactivity of the alkaloids [17].

Several studies have been demonstrating the antiinflammatory activity of alkaloids, involving inhibition or regulation of important inflammation mediators such as NF- $\kappa$ B, COX-2, and iNOS [23-29]. Souto et al. reviewed published studies to evaluate the anti-inflammatory activity of alkaloids and reported 40 of these compounds with significant activity [30]. Antioxidant activity of alkaloids have also been presented in different experimental models or pathological conditions [31-35]. Based on the chemical diversity of alkaloids and their biological activities previously reported, these compounds emerge as potential agents for intestinal inflammatory disorders.

\section{Alkaloids and Experimental Colitis}

This search was carried out on PubMed, Scopus, and Web of Science database, using the terms "Inflammatory Bowel Disease" OR "experimental colitis" OR “ulcerative colitis" OR “Crohn's Disease” OR “Colitis” AND “Alkaloid”. Publications over the last decade were considered.

3.1. Nicotine: Dual Role on IBD. Nicotine is studied as the main compound responsible for cigarette smoking properties on intestinal mucosa [36]. Smoking has an opposite effect in the two forms of IBD: while smoking increases the number and the risk of developing relapses in CD, in UC, surprisingly, the episodes of active disease are decreased [37, 38]. The effect of nicotine on intestinal inflammation has been widely studied in experimental assays [39-42] and clinical trials [43$45]$ and there are several reviews on the effects of nicotine in relation to IBD [46-49].

3.2. Plant Extracts and Herbal Formulation. The search shows some studies with plant extracts or herbal formulations, rich in alkaloids, used in traditional Chinese and Ayurvedic medicine as Amaranthus roxburghianus, Hangeshashinto, Fructus Mume pill, Sangrovit, and Sophora alopecuroides.

Our search on alkaloid and IBD has led to several plant extracts or herbal formulations commonly used in traditional Chinese and Ayurvedic medicine, such as Hangeshashinto (HST), Sophora alopecuroides, Fructus Mume pill (FMP), Sangrovit and, and Amaranthus roxburghianus.

Kawashima and colleagues [50] evaluated a combination of oriental medicinal plants, HST, in TNBS-induced colitis. Wistar rats treated with HST for 5 days presented decreased colon damage (macroscopic lesion score, ulcerative area, and colon weight), reduced diarrhea, and increased body weight. The authors also evaluated the effect of main constituents of HST, berberine (BE), baicalin (BA), glycyrrhizin (GL), and ginsenosides (GS) in the experimental TNBS colitis. These components were given alone, in combination $(\mathrm{BA}+\mathrm{BE}$ and $\mathrm{GL}+\mathrm{GS})$, or in a total mixture $(\mathrm{BA}+\mathrm{BE}+\mathrm{GL}+\mathrm{GS})$. The compounds given alone and the combination $\mathrm{BA}+\mathrm{BE}$ did not prevent colon injury, while GL + GS and the total mixture ameliorated the intestinal inflammation. The authors concluded that neither berberine nor baicalin is responsible for HST anticolitis effect; thus, HST was suggested to prevent or diminish the colitic phenotype due to the synergistic combination of its components.

Effects of total alkaloids of Sophora alopecuroides (TASA) were evaluated in TNBS-induced colitis in rats, by Chen and Deng [51]. TASA ameliorated histological damage, increased SOD activity, and decreased MDA levels, as well as NO and MPO activity. In a study from Zhou and colleagues [52], employing the same experimental model, the oral treatment 


\begin{tabular}{l}
\hline True alkaloids \\
Precursor: L-ornithine
\end{tabular}

Precursor: L-lysine

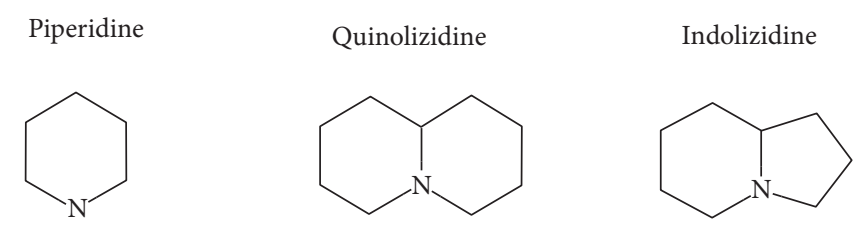

Precursor: L-tryptophan

Indole<smiles>c1ccc2[nH]ccc2c1</smiles>

$\mathrm{H}$
Quinoline<smiles>c1ccc2ncccc2c1</smiles>

pyrroloindole<smiles></smiles>

Precursor: anthranilic acid

$$
\text { Quinazoline }
$$<smiles>c1ccc2ncncc2c1</smiles>

Precursor: L-tyrosine or L-phenylalanine Isoquinoline<smiles>c1ccc2cnccc2c1</smiles>

$$
\text { Quinoline }
$$<smiles>c1ccc2ncccc2c1</smiles>

\section{Acridone}<smiles>O=c1c2ccccc2[nH]c2ccccc12</smiles>

Precursor: L-histidine
Manzamine<smiles>Cn1cncc1C(=O)C1=NCCc2c1[nH]c1ccccc21</smiles>

(a)

Figure 1: Continued. 




(c)

Figure 1: Main alkaloids groups: True Alkaloids (a), Protolakaloids (b) and Pseudoalkaloids (c), precursors, and skeleton structures. Adapted from Aniszewski, 2007 [18]. Chemical structures were getting in PubChem database.

with TASA decreased damage scores, maybe due to the upregulation of CD4+CD25+ regulatory T cells (Tregs) and anti-inflammatory cytokine IL-10.

The effect of TASA on DSS-induced intestinal inflammation in mice has also been investigated. In this model, TASA inhibited acute inflammation in the gut by inhibiting the secretion of IL- $1 \beta$ and promoting the release of antiinflammatory cytokine IL-4 [53]. Zhao et al. [54] assayed
TASA treatment on DSS-induced chronic intestine injury. Chronically, TASA exhibited protective effects on DSS colitis inhibiting secretory immunoglobulin A and haptoglobin release; likewise, the intercellular adhesion molecule 1 (ICAM-1) gene expression and p65 recruitment to the ICAM1 gene promoter were also found inhibited, suggesting that TASA might protect the intestine from injury by inhibiting NF- $\kappa \mathrm{B}$ activation. 
FMP is a combination of ten Chinese herbs that has been used for a long time in traditional Chinese medicine for the treatment of diarrhea and dysentery; indeed, the State Food and Drug Administration of China approved its use for the management of gastrointestinal disorders. The effect of FMP was evaluated on TNBS-induced colitis in SpragueDawley rats. Remarkable results include reduced ulcer area, colon weight/length ratio, diarrhea, colonic MPO activity, INF- $\gamma$ levels, gram -/gram + bacteria relation, and increased IL-4 levels [55]. The authors suggested that these effects may be related to the alkaloids aconitine and berberine. In another study, Zhang and colleagues [56] reported the synergistic activity of three alkaloids from FMP: berberine, hypaconitine, and skimmianine on TNBS-induced colitis in rats. Berberine ameliorated intestinal injury and diminished TNF- $\alpha$ levels and NF- $\kappa$ B expression in colon but had no effect on abdominal pain (in acetic acid-induced writhing) nor gastrointestinal transit. Although hypaconitine and skimmianine did not exhibit anti-inflammatory activity on TNBSinduced colitis, the treatment with the combination of the three alkaloids ameliorated the colonic injury. The authors suggest that berberine exerted mainly anti-inflammatory activity, while hypaconitine possesses analgesic effect and skimmianine antidiarrheal properties.

Vrublova and colleagues [57] assayed the Sangrovit (rich in isoquinoline alkaloids) feeding supplementation in DSSinduced colitis in Wistar rats. Sangrovit is used as appetizer supplement in livestock feed. Sangrovit ameliorated histological damage score, decreasing COX-2 expression and colonic MPO activity. The alkaloids sanguinarine, dihydrosanguinarine, chelerythrine, and dihydrochelerythrine were found in the colon of Sangrovit-treated animals, suggesting a direct effect of these compounds in the colonic mucosae.

Iablokov and colleagues [58] evaluated the effects of potatoes glycoalkaloids on IL-10 knockout mice (genetic predisposition to develop colitis) and DSS treated mice. Their data show increased INF- $\gamma$ levels in ileum of IL-10 knockout mice and increased intestinal permeability and INF- $\gamma$, IL-17, and TNF- $\alpha$ levels in DSS colitis mice. As a consequence, deleterious effects of glycoalkaloids were reported. The authors attributed such effects, mainly, to the compounds $\alpha$-chaconine and $\alpha$-solanine. The glycoalkaloids concentration can raise in about threefold in fried potatoes which has been shown to aggravate intestinal inflammation.

Nirmal and collaborators [59] analyzed the effect of Amaranthus roxburghianus root extract in combination with piperine on acid acetic-induced colonic injury in mice. The treatment with $A$. roxburghianus decreased histopathological damage, MPO activity, and MDA levels and major levels of reduced GSH compared to control (5\% acetic acid). Interestingly, the combination with piperine improved the effects of the extract, similarly to those observed for prednisolonetreated animals while piperine itself had no effect.

In a recent publication, Bribi and colleagues [60] reported the protective effect of total alkaloids of Fumaria capreolata (AFC) on DNBS-induced colitis in mice. AFC treatment decreased the body weight loss, colon weight/length ratio, and microscopic score. AFC inhibited the increase of TNF- $\alpha$, IL-1 $\beta$, Il-6, IL-12, iNOS, ICAM-1, and MMP-9 and prevented the downregulation of MUC-2 mRNA expression in the colon. In LPS-stimulated CMT93 cells, AFC prevented upregulation of of ICAM-1, TNF- $\alpha$, and IL- 6 mRNA expression and the release of TNF- $\alpha$ and IL- 6 . In addition, ACF has also prevented the downregulation of of MUC-2 and ZO-1 expression in LPS-stimulated CMT93 cells. Stylopine, coptisine, and protropine were identified as major compounds in AFC.

3.3. Isolated Alkaloids. We found 32 alkaloids with activity assessed in experimental models that induced the disrupt of the epithelial barrier (DSS, acetic acid, or mustard oil) or that involved hapten-induced hypersensitive reactions in the intestinal inflammation (TNBS), mainly in mice.

In accordance with structural forms, the cited alkaloids are classified in diterpenoid alkaloids (14-O-acetylneoline, 14-O-veratroylpseudaconine, and hypaconitine), indole alkaloids (fumigaclavine $\mathrm{C}$ and isatin), indolonaphthyridine alkaloids (nigakinone), indoloquinazoline alkaloids (tryptanthin), isoquinoline alkaloids (berberine, boldine, cavidine, coptisine derivatives, EM012, papaverine, sanguinarine, sinomenine, tetrahydrocoptisine, and tetrandrine), phenanthroindolizidine alkaloids (NK-007 and W-8), piperidine alkaloids (piperine), purine alkaloids (caffeine), quinoline alkaloids (skimmianine), and quinolizidine alkaloids (matrine, oxymatrine, sophocarpine, and sophoridine). The effects of these alkaloids on experimental colitis are summarized in Table 1. Berberine, sinomenine, and piperine effects on experimental colitis were assessed in two or more manuscripts, as detailed hereafter.

Berberine has been the wieldiest studied alkaloid with pharmacological activity in intestinal inflammatory models. It is one of the main substances of Berberis sp. [95]. It is also isolated from Hydrastis, Coptis, and Phellodendron species [96]. The effect of berberine in colitis was evaluated in DSS and TNBS-induced colitis in mice and rats. This alkaloid ameliorates colon injury and inhibits the increase of inflammatory mediators and oxidative damage, as described in Table 1.

The treatment with berberine was used as reference drug for Berberis vulgaris fruit extract (BFE) treatment during the evaluation of its effects on acetic acid-induced colitis [65]. Both oral BFE and enema treatment were effective in diminishing the macroscopic and histopathological damage. As BFE is nearly disproved of berberine alkaloid, the authors attributed the effect to other components, such as anthocyanins. Kawashima and collaborators [50] reported no significant effect of berberine ( 3.75 or $6.5 \mathrm{mg} \cdot \mathrm{kg}^{-1}$ ) treatment in TNBS-induced colitis. This result is probably due to the doses used, while the protective effect of berberine in experimental colitis was observed with doses of $10-100 \mathrm{mg} \cdot \mathrm{kg}^{-1}[64,66,67$, 69].

The addition of berberine $\left(20 \mathrm{mg} \cdot \mathrm{kg}^{-1}\right)$ to 5 -ASA treatment $\left(200 \mathrm{mg} \cdot \mathrm{kg}^{-1}\right)$ decreased disease severity of colitis induced by DSS in mice. 5-ASA in combination with berberine decreased the disease activity index (DAI) and histological injury, inhibited COX-2, TNF- $\alpha$, IL-12b, and IL-23 expression in colon tissue, and inhibited NF- $\kappa \mathrm{B}$ and JAK activation. Moreover, the combination of 5-ASA and 

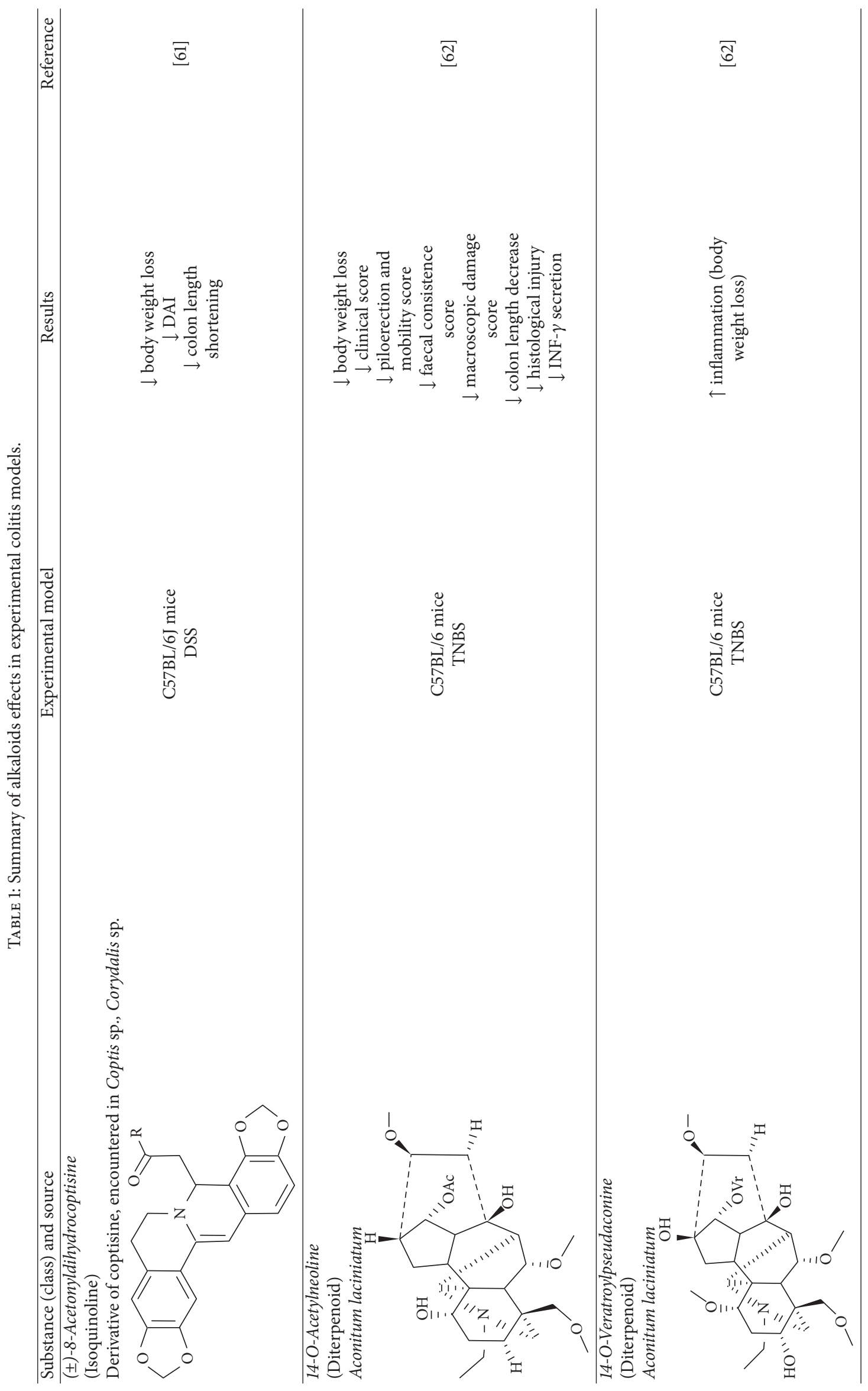


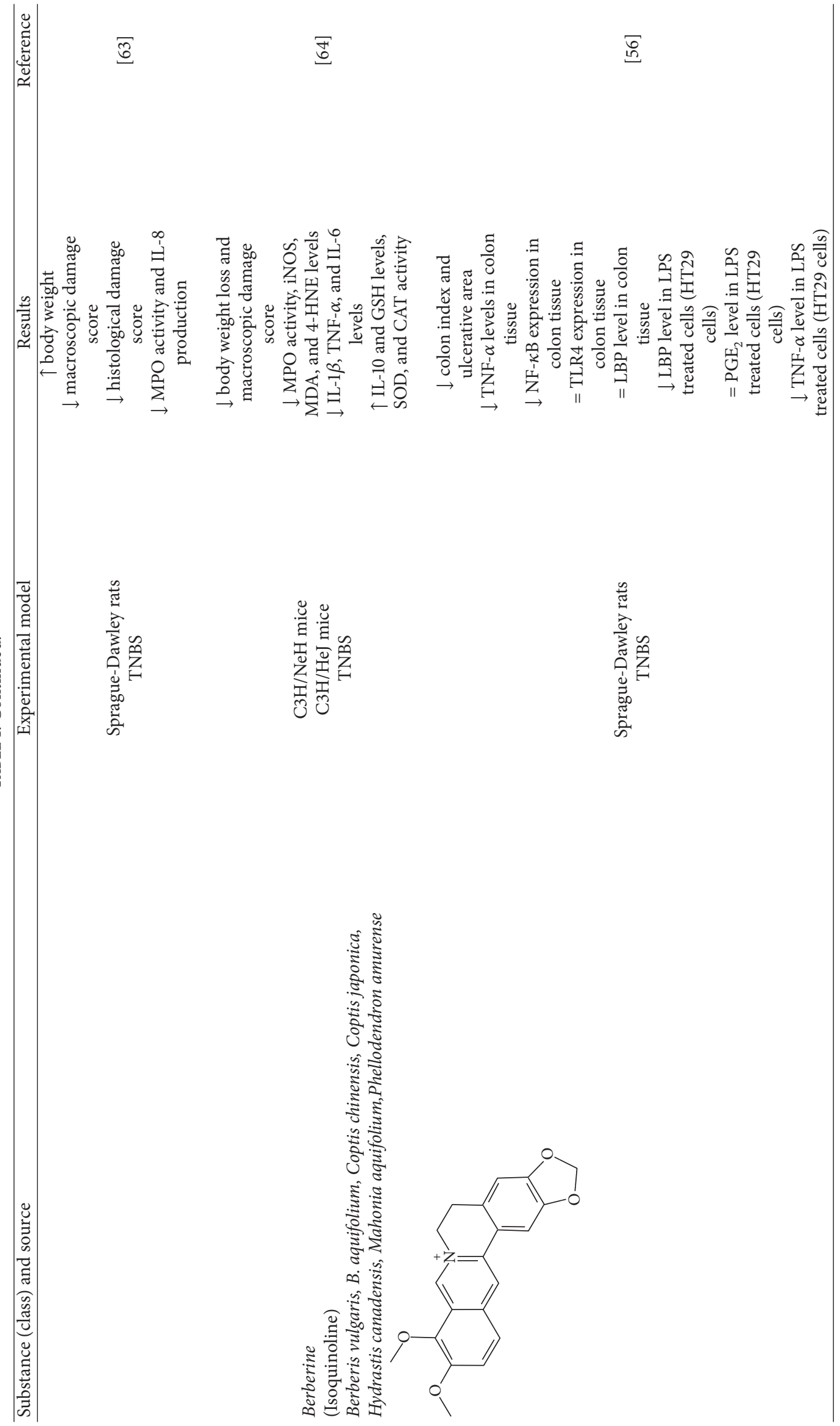




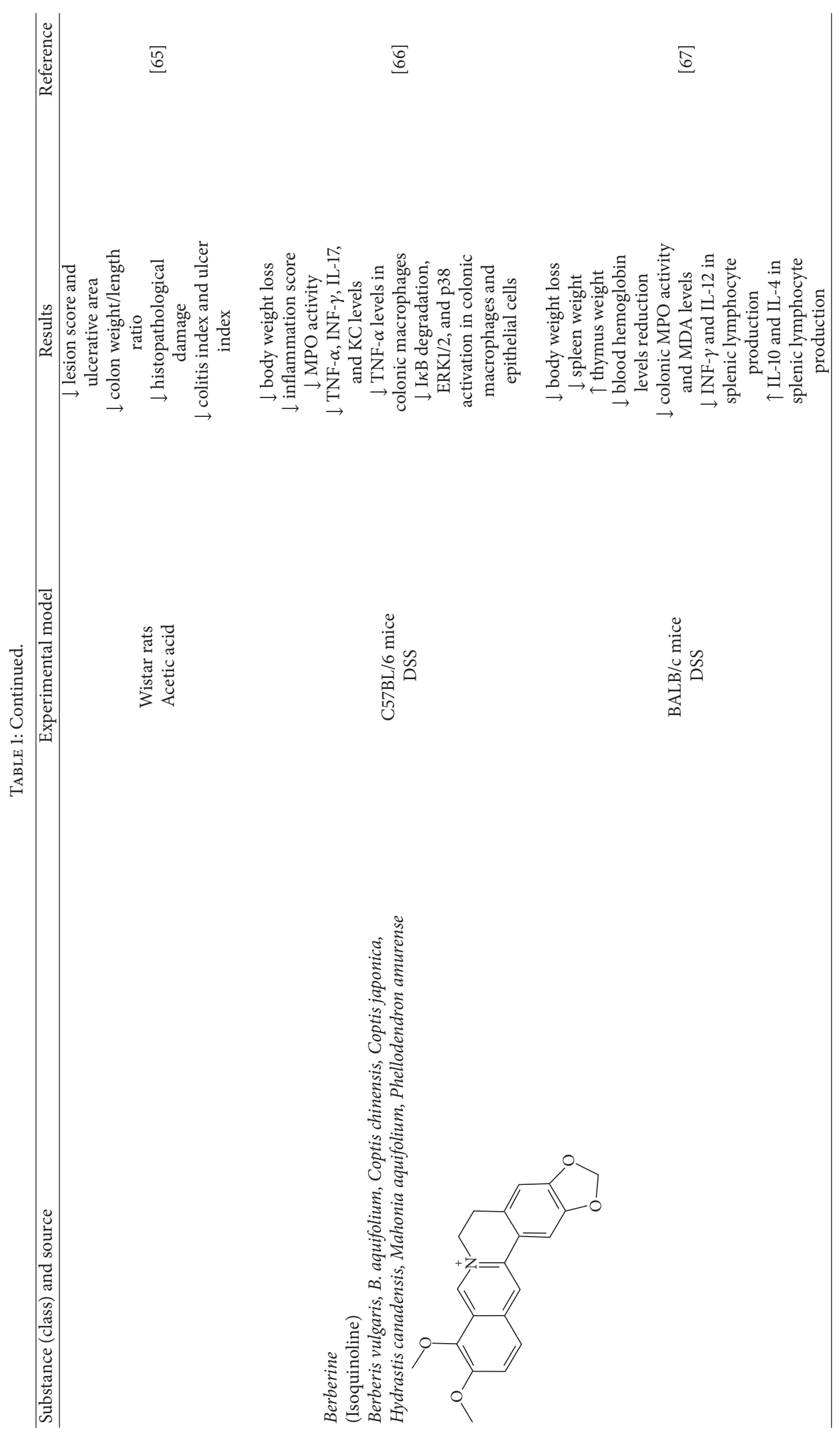




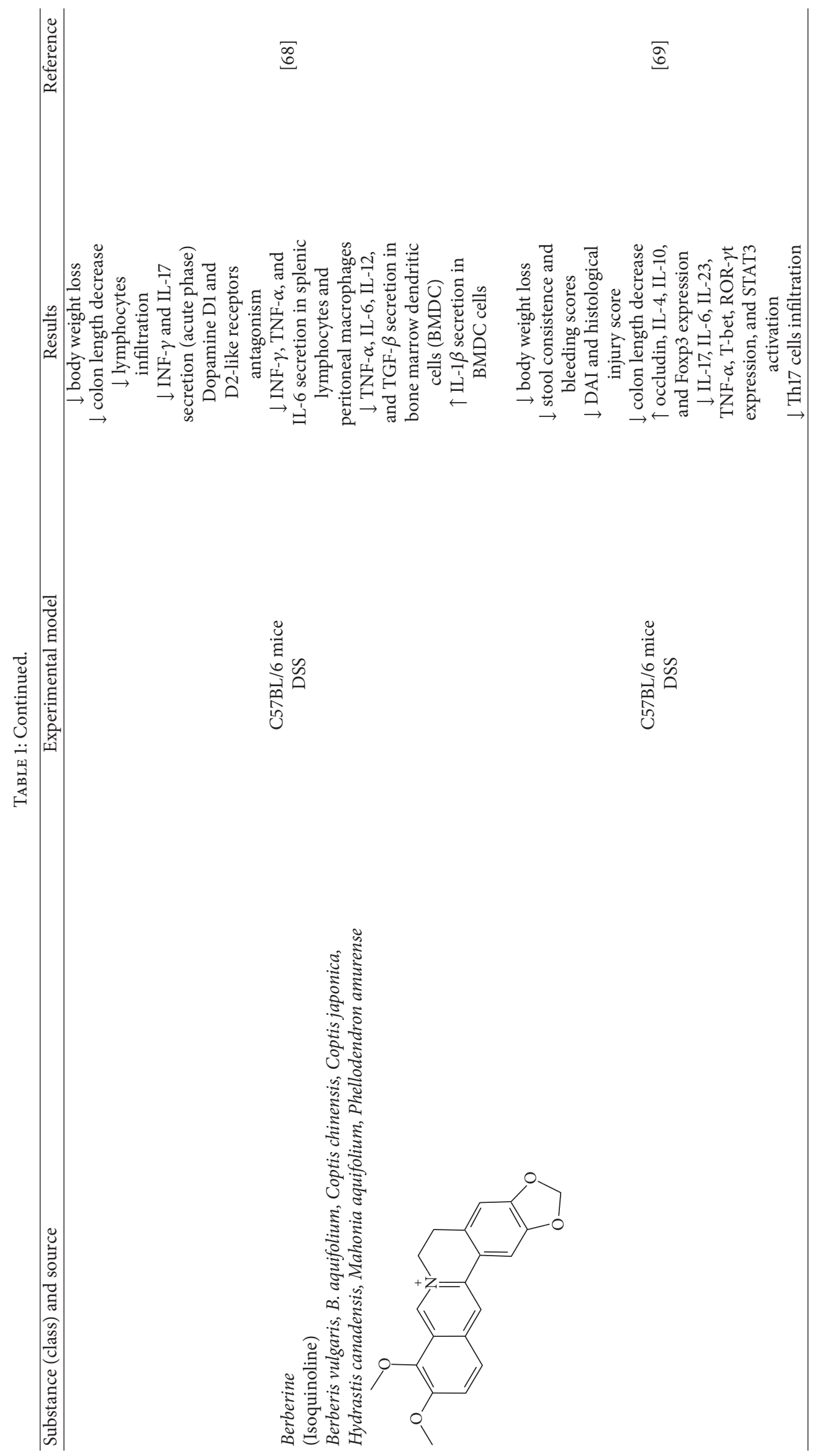




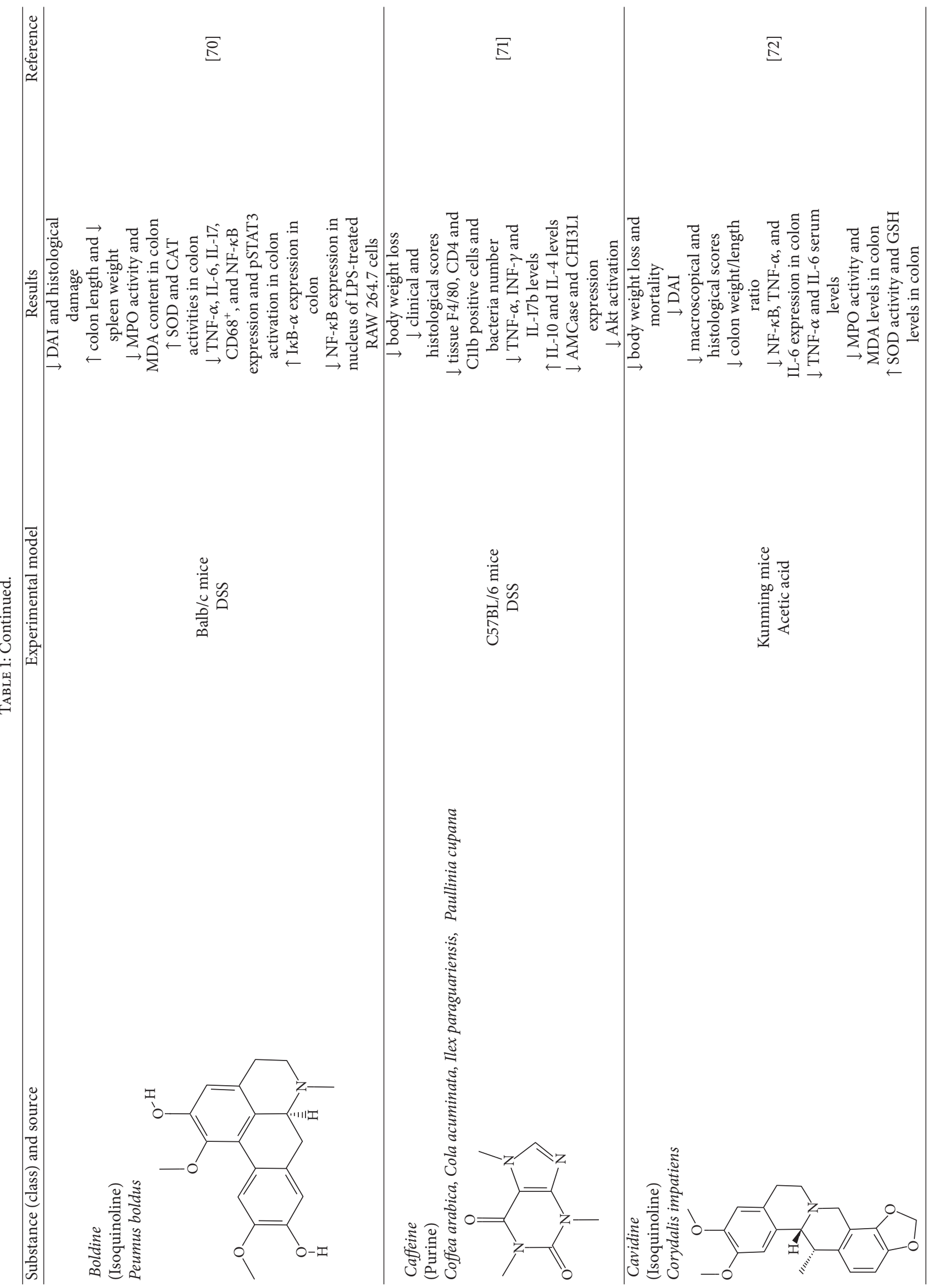




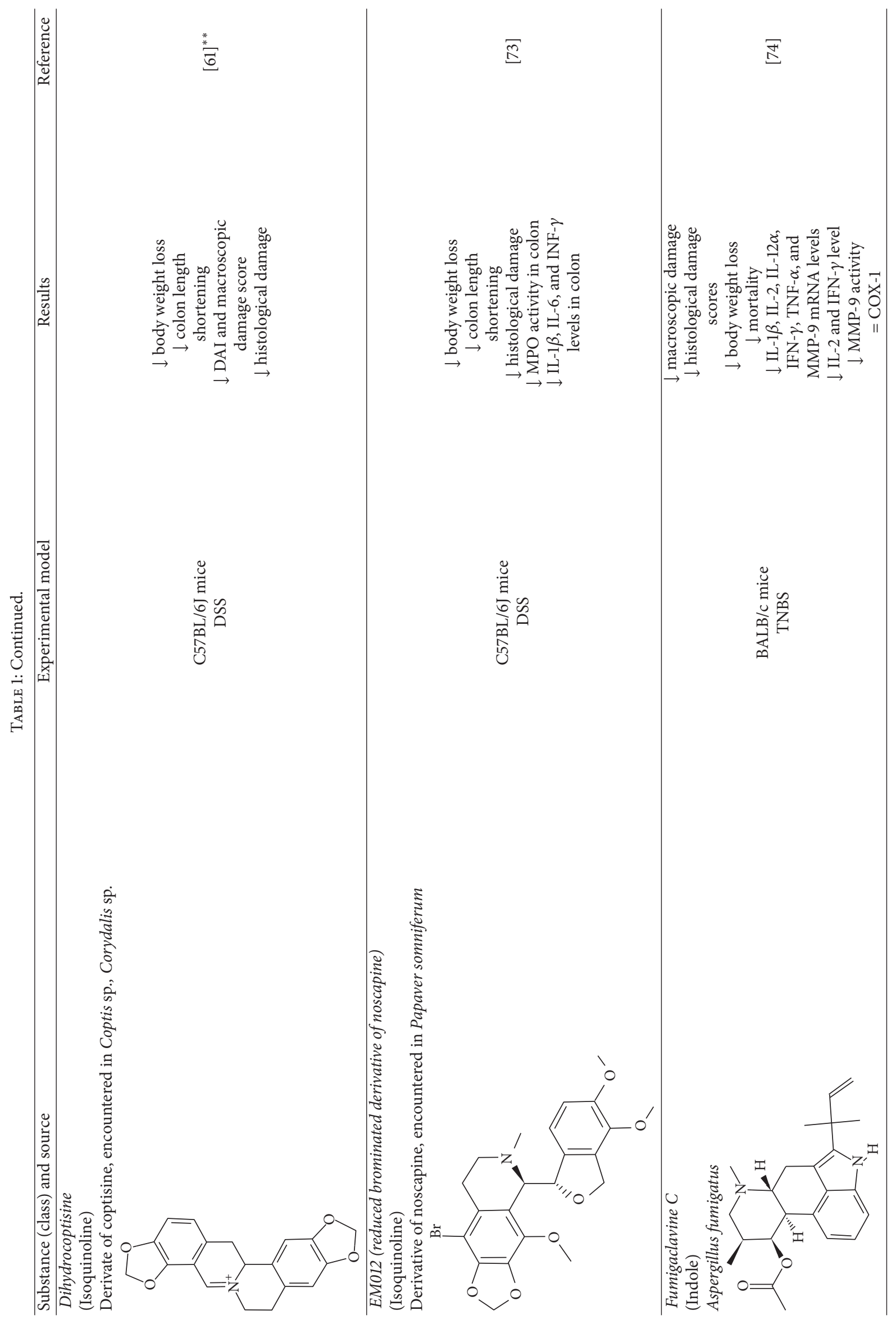




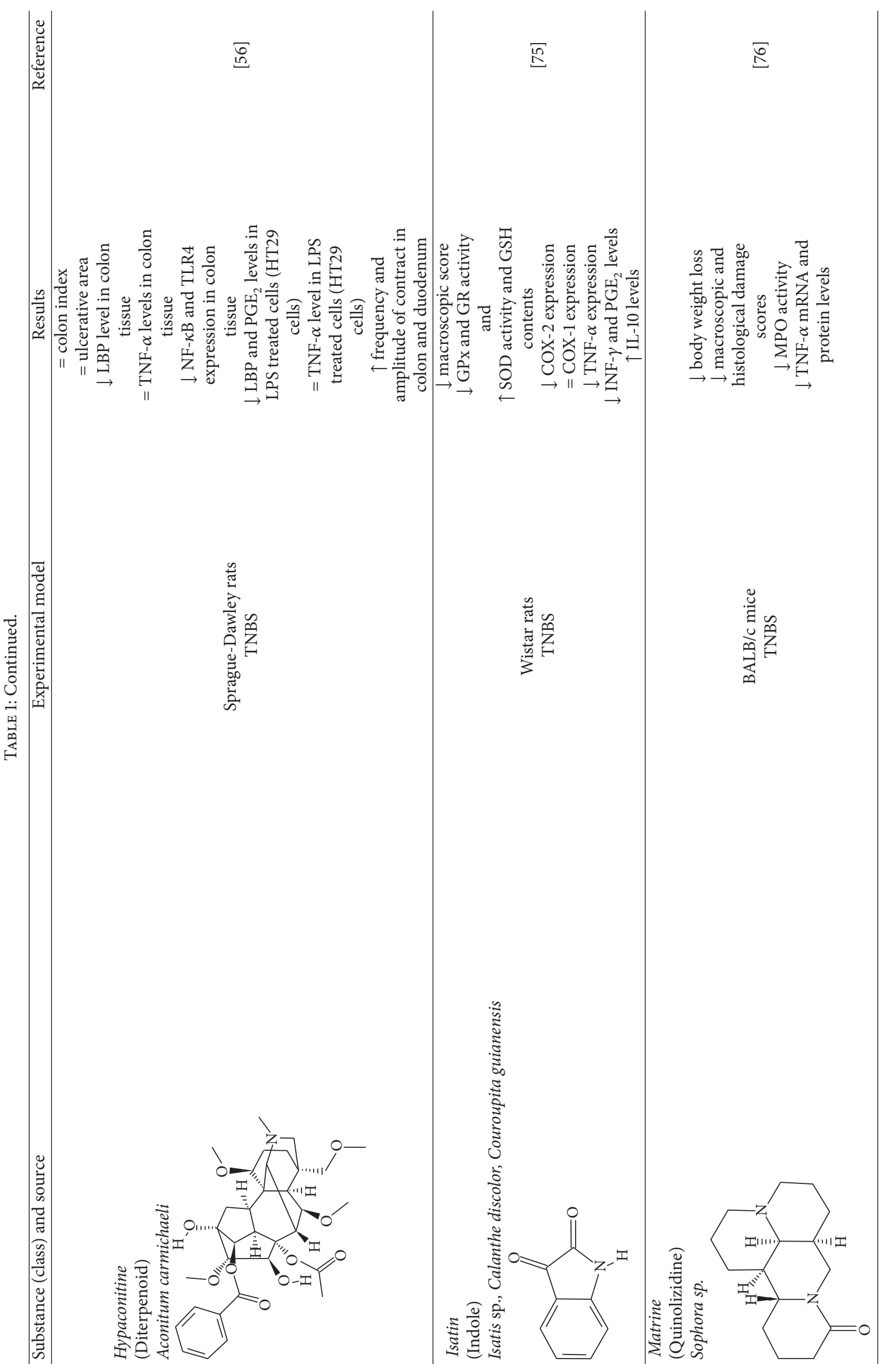









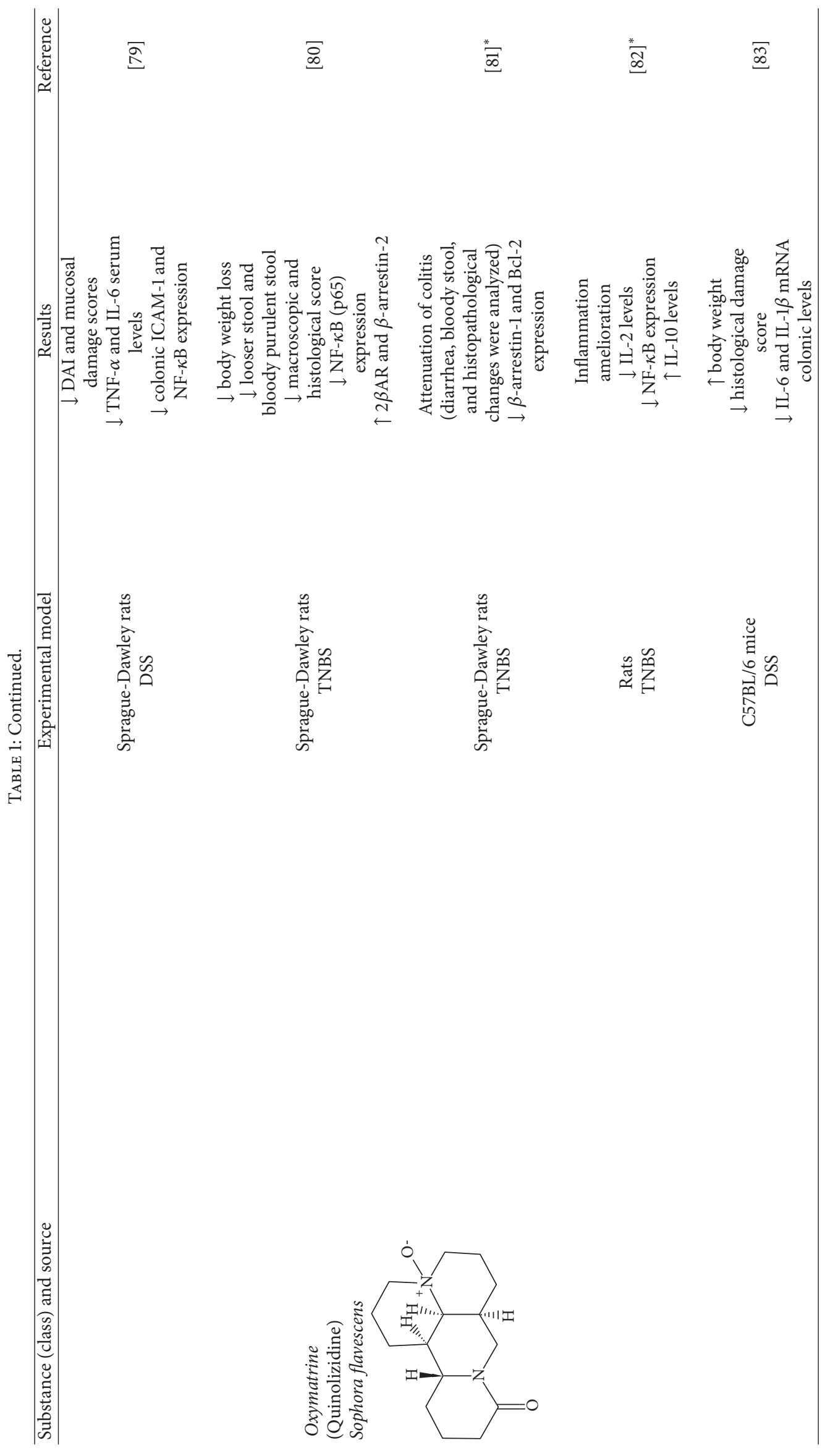




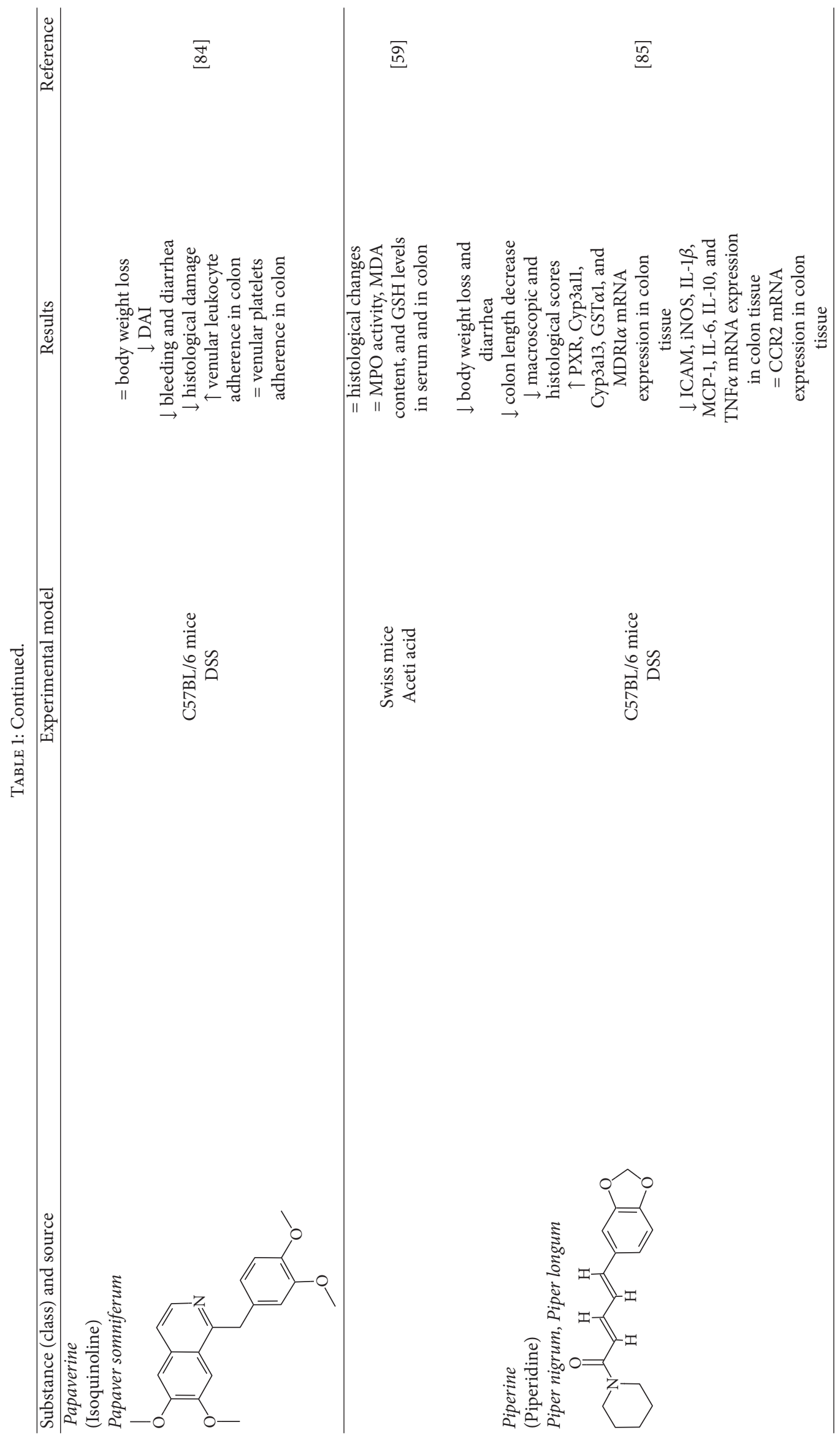




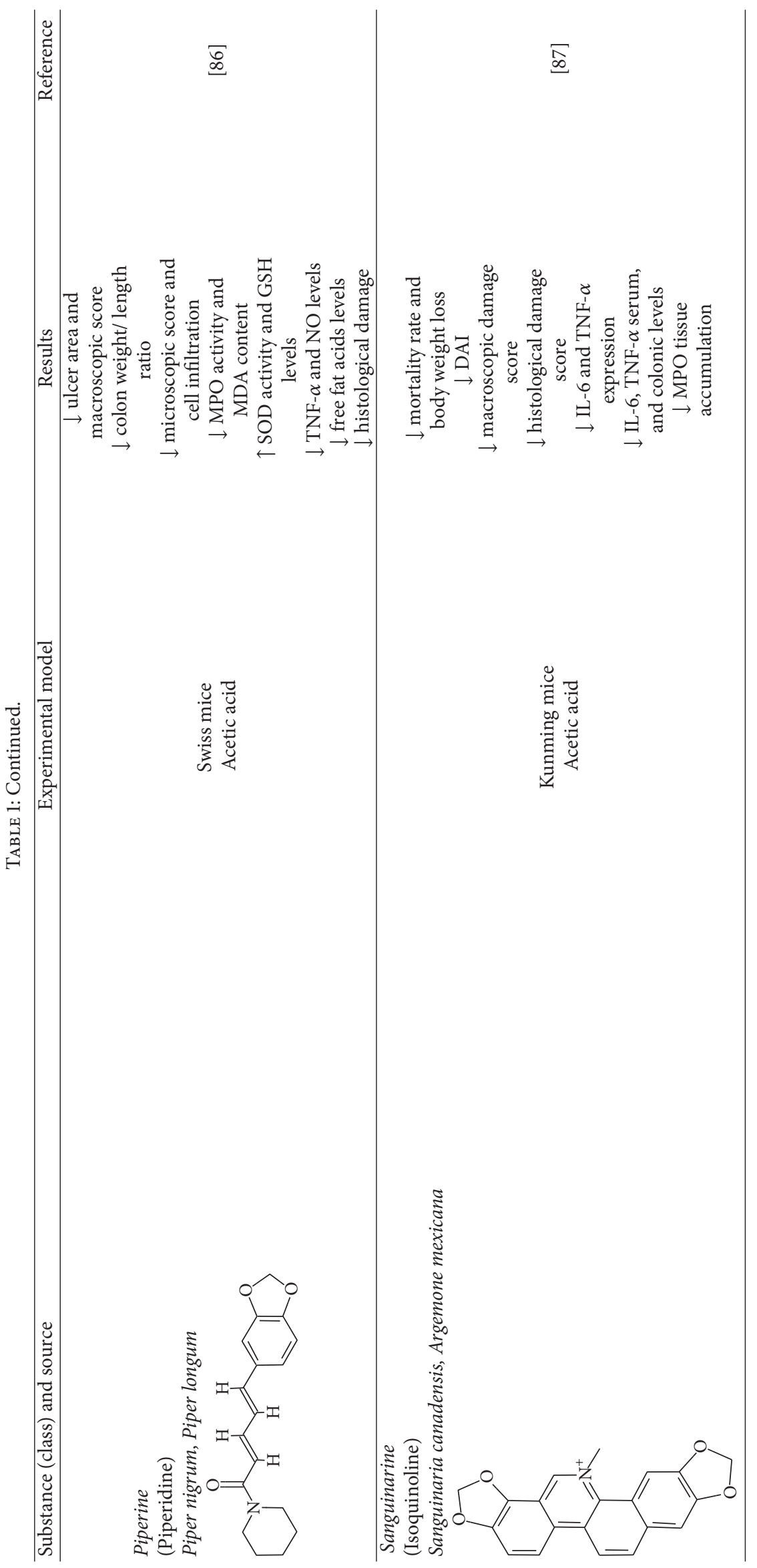




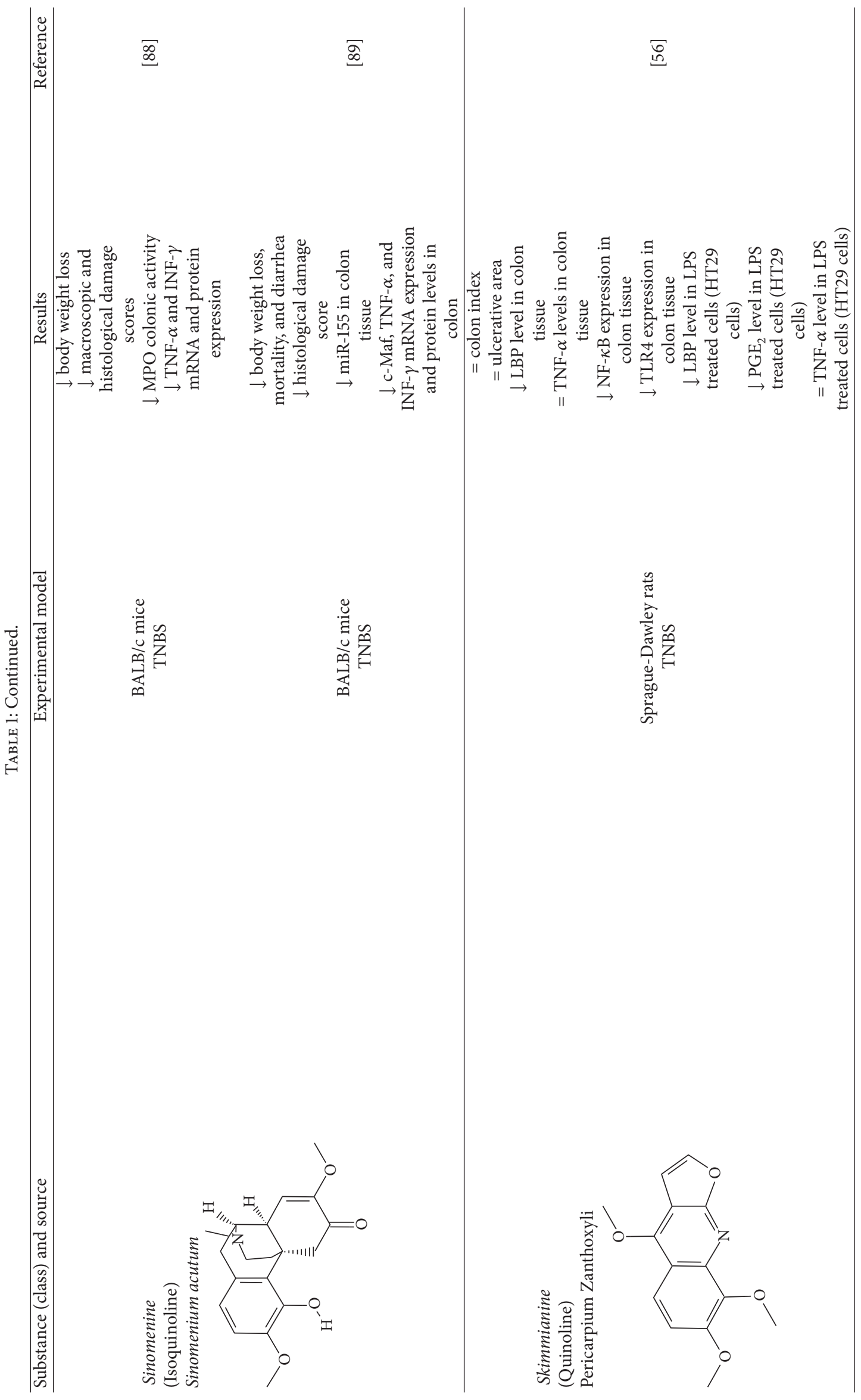




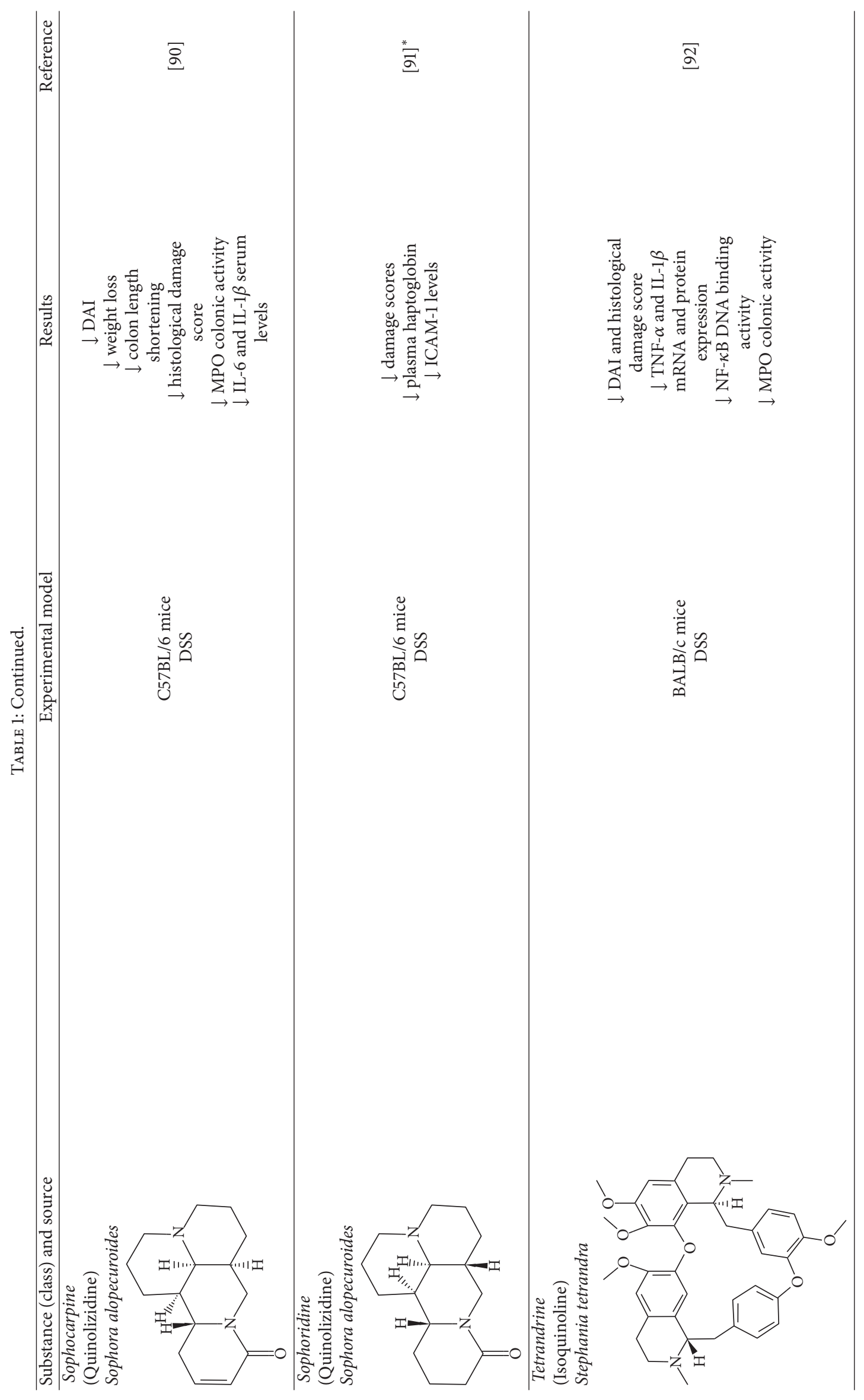




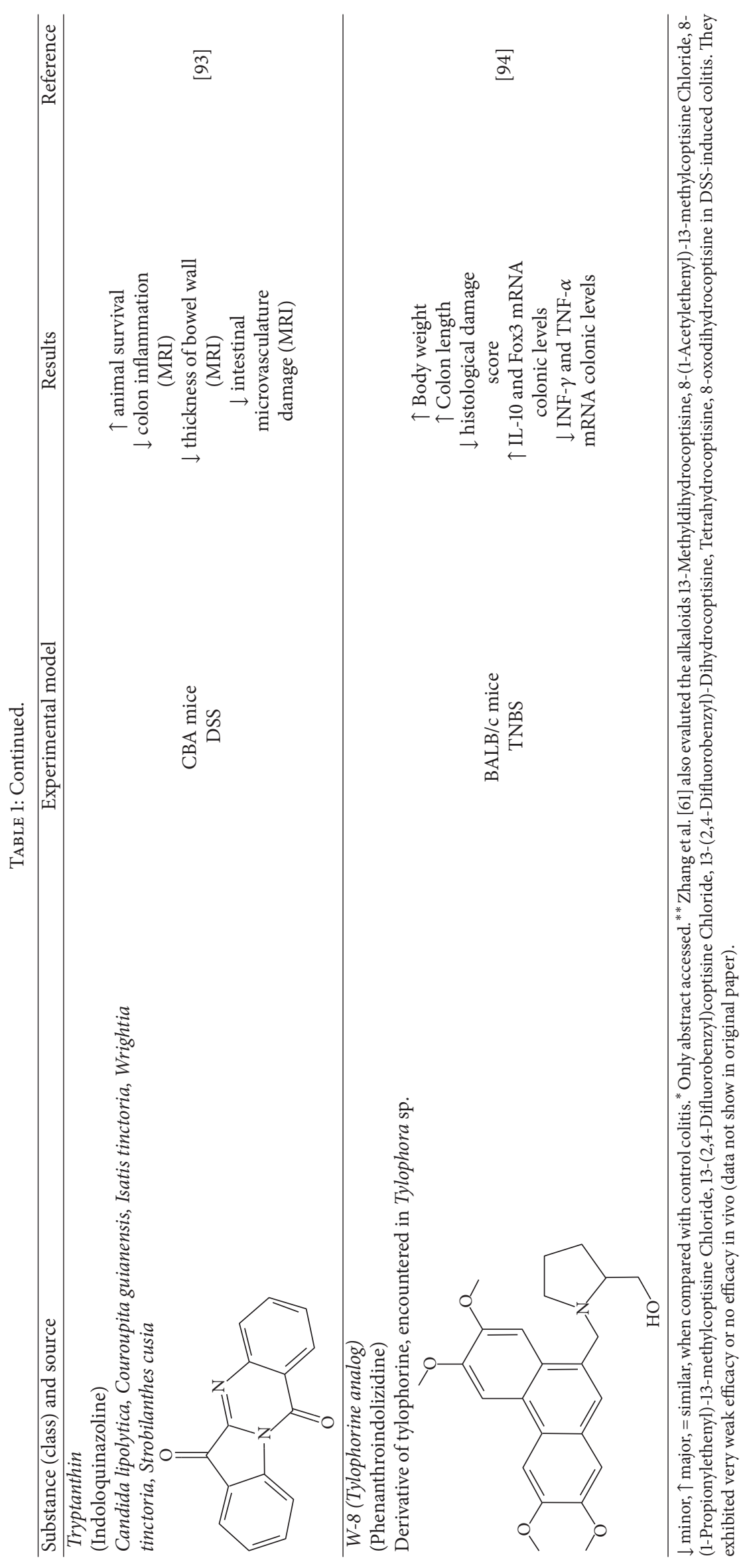


berberine did not produce any deleterious effects in mice. The authors suggest that the combination is promising to UC therapy.

Berberine is an isoquinoline quaternary alkaloid and presents therapeutic properties, as antimicrobial, antidiabetic, anticancer, and anti-inflammatory, and has pharmacological activity in gastroenteritis, abdominal pain, and diarrhea [28, 31, 97]. Berberine also improves intestinal epithelial tight junction integrity, as presented by $\mathrm{Gu}$ et al. [98]. This study proposes reduced epithelial gut permeability as a possible mechanism of antidiarrheic activity of berberine. DiGuilio and colleagues [99] tested berberine treatment, in vitro, using CACO-2 cells barrier leaking induced by cytokines (TNF- $\alpha$, IL- $1 \beta$, and INF- $\gamma$ ) or hydrogen peroxide. Berberine enhanced basal CACO-2 barrier integrity and also decreased cytokine-induced injury in epithelial barrier function, suggesting that this phenomenon might also contribute to the role of berberine on experimental model of colitis.

The alkaloid oxymatrine activity in experimental colitis was reported in four articles [79-81, 83]. The treatment with oxymatrine improves TNBS and DSS-induced colitis. The protective effect of oxymatrine was also evaluated in intestinal injury induced by ischemia and reperfusion. The authors reported decreased apoptosis index, intestinal lipid peroxidation, serum TNF- $\alpha$ levels, phosphorylated p38 mitogenactivated protein kinase (MAPK), and Fas/FasL expression [100].

Sinomenine activity in experimental colitis was reported in two manuscripts $[88,89]$. This alkaloid inhibits the generation of inflammatory mediators in TNBS-induced colitis in mice. In experimental model of colitis, sinomenine has been suggested to downregulate microRNA 155 (MiR-155), the transcription factor c-Maf, and the cytokines TNF- $\alpha$ and IFN- $\gamma$. Sinomenine has also demonstrated analgesic activity on neuropathic and inflammatory pain models [101], suppressive effect on colon carcinoma cell growth [102, 103], and anti-inflammatory activity [104].

Li and collaborators [105] employed the alkaloid piperine to ameliorate curcumin absorption and pharmacological activity. Piperine and curcumin were encapsulated in a nanoformulation, called self-microemulsifying drug delivery system (CUR-PIP-SMEDDS). The system CUR-PIP-SMEDDS increased the drug stability and the dissolution of curcumin at the colon site (in vitro) and showed therapeutic effects in DSS-induced colitis in mice. CUR-PIP-SMEDDS decreased DAI, histopathological lesions, MPO activity, MDA content, TNF- $\alpha$, and IL- 6 levels in colonic tissue of mice.

In a study from $\mathrm{Hu}$ et al. [85], the evaluation of the mechanisms of action of piperine on DSS-induced colitis allowed the development of siRNA-mediated knockdown of PXR in mouse colons and also indicated a role of PXR in protecting colonic mucosae. Piperine treatment prevented body weight loss, diarrhea, histological injury, and the expression of inflammatory mediators on DSS-induced colitis in mice. When the PXR was downregulated, the DSS injury was exacerbated and piperine protection against DSS colitis was inhibited.

We found two studies with comparative analysis of several alkaloids in experimental colitis. Wangchuk et al.
[62] isolated five diterpenoids alkaloids (pseudaconitine, 14-veratroylpseudaconine, 14-O-acetylneoline, neoline, and senbusine A) of Aconitum laciniatum, a species of aconites of polyherbal formulations in Bhutanese Traditional Medicine, for inflammatory conditions. In this work, the authors reported the evaluation of 14-veratroylpseudaconine and 14-O-acetylneoline in TNBS-induced colitis in mice. The compound 14-veratroylpseudaconine exacerbated the TNBSinduced damage, while 14-O-acetylneoline ameliorated some signals of injury and inhibited the INF- $\gamma$ release. In the manuscript of Zhang et al. [61], thirty synthesized coptisine derivatives were found to activate the in vitro transcription of $\mathrm{x}$-box-binding protein 1 (XBP1). The dihydrocoptisines were demonstrated to be much more active antiulcerative colitis agents than quaternary coptisines and tetrahydrocoptisines, by in vitro XBP1 transcriptional activity assays and animal experiments (DSS-induced colitis). The authors also demonstrated that reductive states and the substitution patterns of the dihydrocoptisines are critical for their efficacy; unsubstituted dihydrocoptisine exhibited more significant efficacy in mice colitis than dihydrocoptisines substituted at the $\mathrm{C}-8$ or $\mathrm{C}-13$ position.

\section{Discussion}

In the present search, alkaloids of different groups showed protective activity in experimental colitis, involving distinct mechanisms. Some alkaloids did not present significant effects in colitis, whereas others, as potatoes glycoalkaloids, exhibited deleterious action in IBD. The majority of the alkaloids studied in experimental colitis were isolated from herbal formulations and plant preparations used in traditional eastern medicine. The evaluation of these extracts in experimental colitis showed their significant and beneficial activity. The latter isolation and study of the components of the effective extract identified some alkaloid with potential activity in IBD. Among them, the berberine was the most reported and the most cited in a review of alkaloid antiinflammatory activity [30]. This manuscript related 40 alkaloids to active effects in different models of inflammation.

IBD therapy includes aminosalicylates, corticosteroids, immunosuppressive agents, and biological agents. Aminosacicylates and corticosterois do not provide long-term clinical response and mucosal healing and immunosuppressors do not induce remission [106]. The anti-TNF- $\alpha$ drugs infliximab and adalimumab improved IBD therapy. They have been shown to induce clinical and endoscopic remission in both CD and UC, to diminish exacerbations and surgery rates [107]. However, one-third of IBD patients are unresponsive to TNF- $\alpha$ antibodies and another third of patients become nonresponsive after a time of treatment. Efficacious treatment options for these patients are imperative [108].

Natural products can be a source of immune modulators antioxidants and anti-inflammatory substances [97, 109-111]. The berberine decreased colonic inflammation in UC and CD experimental models and inhibited cytokines release (TNF- $\alpha$, IL-1 $\beta$, IL-6, IL-12, and IL17). This effect can be promising to IBD therapy, but there are no clinical studies 
related to berberine in IBD. This isoquinoline alkaloid has been evaluated in different clinical trial studies and is showed to decrease symptoms of irritable bowel syndrome [112], nonalcoholic fatty liver disease [113], and acute coronary syndrome inflammation [114] without any side effects related to berberine treatment.

The combination of therapeutic drugs and alkaloids may be an approach of induction of remission, with fewer collateral effects. A minor dose of 5-ASA showed protective effect in mice DSS colitis, in a combination with berberine [115]. Abdel-Daim and collaborators highlighted the role of natural products in ameliorating collateral effects of standard drugs [116]. However, it is important to regard alkaloids toxicity and safety to human use.

The study of alkaloid properties in IBD may contribute to the development of new drugs. Considering the variety of structures and the biological effects of alkaloids, antiinflammatory and antioxidant activity reported, and the small number of published articles, there is still much to be explored in this chemical class in IBD.

\section{Competing Interests}

The authors declare that they have no competing interests.

\section{References}

[1] B. A. Hendrickson, R. Gokhale, and J. H. Cho, "Clinical aspects and pathophysiology of inflammatory bowel disease," Clinical Microbiology Reviews, vol. 15, no. 1, pp. 79-94, 2002.

[2] S. Danese and C. Fiocchi, "Ulcerative colitis," The New England Journal of Medicine, vol. 365, no. 18, pp. 1713-1725, 2011.

[3] D. C. Baumgart and W. J. Sandborn, "Crohn's disease," The Lancet, vol. 380, no. 9853, pp. 1590-1605, 2012.

[4] S. Ardizzone and G. Bianchi Porro, "Inflammatory bowel disease: new insights into pathogenesis and treatment," Journal of Internal Medicine, vol. 252, no. 6, pp. 475-496, 2002.

[5] M. I. Torres and A. Ríos, "Current view of the immunopathogenesis in inflammatory bowel disease and its implications for therapy," World Journal of Gastroenterology, vol. 14, no. 13, pp. 1972-1980, 2008.

[6] A. Kaser, S. Zeissig, and R. S. Blumberg, "Genes and environment: how will our concepts on the pathophysiology of IBD develop in the future?" Digestive Diseases, vol. 28, no. 3, pp. 395405, 2010.

[7] N. A. Molodecky, I. S. Soon, D. M. Rabi et al., "Increasing incidence and prevalence of the inflammatory bowel diseases with time, based on systematic review," Gastroenterology, vol. 142, no. 1, pp. 46.e42-54.e42, 2012.

[8] T. Yamamoto, M. Nakahigashi, and A. R. Saniabadi, "Review article: diet and inflammatory bowel disease-epidemiology and treatment," Alimentary Pharmacology \& Therapeutics, vol. 30, no. 2, pp. 99-112, 2009.

[9] C. N. Bernstein, "Treatment of IBD: where we are and where we are going," The American Journal of Gastroenterology, vol. 110, no. 1, pp. 114-126, 2015.

[10] M. Fakhoury, R. Negrulj, A. Mooranian, and H. Al-Salami, "Inflammatory bowel disease: clinical aspects and treatments," Journal of Inflammation Research, vol. 7, no. 1, pp. 113-120, 2014.
[11] S. Ben-Horin and Y. Chowers, "Review article: loss of response to anti-TNF treatments in Crohn's disease," Alimentary Pharmacology and Therapeutics, vol. 33, no. 9, pp. 987-995, 2011.

[12] D. D. Baker, M. Chu, U. Oza, and V. Rajgarhia, "The value of natural products to future pharmaceutical discovery," Natural Product Reports, vol. 24, no. 6, pp. 1225-1244, 2007.

[13] J. Chen, W. Li, H. Yao, and J. Xu, "Insights into drug discovery from natural products through structural modification," Fitoterapia, vol. 103, pp. 231-241, 2015.

[14] D. J. Newman and G. M. Cragg, "Natural products as sources of new drugs over the 30 years from 1981 to 2010," Journal of Natural Products, vol. 75, no. 3, pp. 311-335, 2012.

[15] R. Rahimi, S. Mozaffari, and M. Abdollahi, "On the use of herbal medicines in management of inflammatory bowel diseases: a systematic review of animal and human studies," Digestive Diseases and Sciences, vol. 54, no. 3, pp. 471-480, 2009.

[16] J. Ziegler and P. J. Facchini, "Alkaloid biosynthesis: metabolism and trafficking," Annual Review of Plant Biology, vol. 59, pp. 735769, 2008.

[17] T. P. T. Cushnie, B. Cushnie, and A. J. Lamb, "Alkaloids: an overview of their antibacterial, antibiotic-enhancing and antivirulence activities," International Journal of Antimicrobial Agents, vol. 44, no. 5, pp. 377-386, 2014.

[18] T. Aniszewski, Alkaloids-Secrets of Life, Alkaloid Chenmistry, Biological Siginificance, Applications and Ecological Role, Elsevier, Amsterdam, The Netherlands, 1st edition, 2007.

[19] W. C. Evans, "Alkaloids," in Trease and Evans' Pharmacognosy, p. 612, WB Sauders Company, London, UK, 1996.

[20] A. Staniek, H. Bouwmeester, P. D. Fraser et al., "Natural products-modifying metabolite pathways in plants," Biotechnology Journal, vol. 8, no. 10, pp. 1159-1171, 2013.

[21] A. T. Henriques, S. O. Lopes, J. T. Paranhos et al., "N, $\beta$-Dglucopyranosyl vincosamide, a light regulated indole alkaloid from the shoots of Psychotria leiocarpa," Phytochemistry, vol. 65, no. 4, pp. 449-454, 2004.

[22] H. de Sousa Falcão, J. A. Leite, J. M. Barbosa-Filho et al., "Gastric and duodenal antiulcer activity of alkaloids: a review," Molecules, vol. 13, no. 12, pp. 3198-3223, 2008.

[23] C.-W. Yang, W.-L. Chen, P.-L. Wu, H.-Y. Tseng, and S.-J. Lee, "Anti-inflammatory mechanisms of phenanthroindolizidine alkaloids," Molecular Pharmacology, vol. 69, no. 3, pp. 749-758, 2006.

[24] C. R. Pradeep and G. Kuttan, "Piperine is a potent inhibitor of nuclear factor- $\kappa \mathrm{B}$ (NF- $\kappa \mathrm{B})$, c-Fos, CREB, ATF-2 and proinflammatory cytokine gene expression in B16F-10 melanoma cells," International Immunopharmacology, vol. 4, no. 14, pp. 17951803, 2004.

[25] M. E. Matheus, F. D. A. Violante, S. J. Garden, A. C. Pinto, and P. D. Fernandes, "Isatins inhibit cyclooxygenase-2 and inducible nitric oxide synthase in a mouse macrophage cell line," European Journal of Pharmacology, vol. 556, no. 1-3, pp. 200-206, 2007.

[26] Z. Zhao, J. Xiao, J. Wang, W. Dong, Z. Peng, and D. An, "Anti-inflammatory effects of novel sinomenine derivatives," International Immunopharmacology, vol. 29, no. 2, pp. 354-360, 2015.

[27] D.-P. Chen, C.-K. Wong, P.-C. Leung et al., "Anti-inflammatory activities of Chinese herbal medicine sinomenine and Liang Miao San on tumor necrosis factor- $\alpha$-activated human fibroblast-like synoviocytes in rheumatoid arthritis," Journal of Ethnopharmacology, vol. 137, no. 1, pp. 457-468, 2011. 
[28] Y. Zhou, S.-Q. Liu, L. Yu et al., "Berberine prevents nitric oxideinduced rat chondrocyte apoptosis and cartilage degeneration in a rat osteoarthritis model via AMPK and p38 MAPK signaling," Apoptosis, vol. 20, no. 9, pp. 1187-1199, 2015.

[29] M. T. Pacheco de Oliveira, T. R. de Oliveira Ramalho, L. K. L. Paiva Ferreira et al., "Synthesis, toxicity study and antiinflammatory effect of MHTP, a new tetrahydroisoquinoline alkaloid," Immunopharmacology and Immunotoxicology, vol. 37, no. 4, pp. 400-412, 2015.

[30] A. L. Souto, J. F. Tavares, M. S. Da Silva, M. F. F. M. De Diniz, P. F. De Athayde-Filho, and J. M. Barbosa Filho, "Anti-inflammatory activity of alkaloids: an update from 2000 to 2010," Molecules, vol. 16, no. 10, pp. 8515-8534, 2011.

[31] A. Shirwaikar, A. Shirwaikar, K. Rajendran, and I. S. R. Punitha, "In vitro antioxidant studies on the benzyl tetra isoquinoline alkaloid berberine," Biological and Pharmaceutical Bulletin, vol. 29, no. 9, pp. 1906-1910, 2006.

[32] R. Gupta and V. Sharma, "Ameliorative effects of Tinospora Cordifoliaroot extract on histopathological and biochemical changes induced by Aflatoxin- $\mathrm{B}_{1}$ in mice kidney," Toxicology International, vol. 18, no. 2, pp. 94-98, 2011.

[33] E. Farias-Silva, M. Cola, T. R. Calvo et al., "Antioxidant activity of indigo and its preventive effect against ethanol-induced DNA damage in rat gastric mucosa," Planta Medica, vol. 73, no. 12, pp. 1241-1246, 2007.

[34] D. Li, J. Guo, W. Bin et al., "Two new benzylisoquinoline alkaloids from Thalictrumfoliolosum and their antioxidant and in vitro antiproliferative properties," Archives of Pharmacal Research, vol. 39, no. 7, pp. 871-877, 2016.

[35] G. A. Czapski, W. Szypuła, M. Kudlik et al., "Assessment of antioxidative activity of alkaloids from Huperzia selago and Diphasiastrum complanatum using in vitro systems," Folia Neuropathologica, vol. 52, no. 4, pp. 394-406, 2014.

[36] M. C. Aldhous, C. L. Noble, and J. Satsangi, "Dysregulation of human $\beta$-defensin-2 protein in inflammatory bowel disease," PLoS ONE, vol. 4, no. 7, Article ID e6285, 2009.

[37] G. Bastida and B. Beltrán, "Ulcerative colitis in smokers, nonsmokers and ex-smokers," World Journal of Gastroenterology, vol. 17, no. 22, pp. 2740-2747, 2011.

[38] S. E. Lakhan and A. Kirchgessner, "Anti-inflammatory effects of nicotine in obesity and ulcerative colitis," Journal of Translational Medicine, vol. 9, no. 1, article no. 129, 2011.

[39] H. Yoshikawa, M. Kurokawa, N. Ozaki et al., "Nicotine inhibits the production of proinflammatory mediators in human monocytes by suppression of I- $\kappa \mathrm{B}$ phosphorylation and nuclear factor- $\kappa \mathrm{B}$ transcriptional activity through nicotinic acetylcholine receptor $\alpha 7$," Clinical \& Experimental Immunology, vol. 146, no. 1, pp. 116-123, 2006.

[40] J. K. S. Ko and C.-H. Cho, "The diverse actions of nicotine and different extracted fractions from tobacco smoke against hapten-induced colitis in rats," Toxicological Sciences, vol. 87, no. 1, pp. 285-295, 2005.

[41] G. R. Abdrakhmanova, M. Kang, M. Imad Damaj, and H. I. Akbarali, "Nicotine suppresses hyperexcitability of colonic sensory neurons and visceral hypersensivity in mouse model of colonic inflammation," American Journal of Physiology, vol. 302, no. 7, pp. G740-G747, 2012.

[42] I. Murakami, Y. Hamada, S. Yamane, H. Fujino, S. Horie, and T. Murayama, "Nicotine-induced neurogenic relaxation in the mouse colon: changes with dextran sodium sulfate-induced colitis," Journal of Pharmacological Sciences, vol. 109, no. 1, pp. 128-138, 2009.
[43] J. R. Ingram, G. A. O. Thomas, J. Rhodes et al., "A randomized trial of nicotine enemas for active ulcerative colitis," Clinical Gastroenterology and Hepatology, vol. 3, no. 11, pp. 1107-1114, 2005.

[44] J. R. Ingram, P. Routledge, J. Rhodes et al., "Nicotine enemas for treatment of ulcerative colitis: a study of the pharmacokinetics and adverse events associated with three doses of nicotine," Alimentary Pharmacology and Therapeutics, vol. 20, no. 8, pp. 859-865, 2004.

[45] J. R. Ingram, J. Rhodes, P. W. Collins, G. T. Williams, R. G. Newcombe, and G. A. O. Thomas, "Plasma fibrinogen in ulcerative colitis: the effect of disease activity and nicotine therapy in a randomised controlled trial," Digestive and Liver Disease, vol. 37, no. 11, pp. 832-837, 2005.

[46] G. J. Johnson, J. Cosnes, and J. C. Mansfield, "Review article: smoking cessation as primary therapy to modify the course of Crohn's disease," Alimentary Pharmacology and Therapeutics, vol. 21, no. 8, pp. 921-931, 2005.

[47] A. Karban and R. Eliakim, "Effect of smoking on inflammatory bowel disease: is it disease or organ specific?" World Journal of Gastroenterology, vol. 13, no. 15, pp. 2150-2152, 2007.

[48] P. C. Lunney and R. W. L. Leong, "Review article: ulcerative colitis, smoking and nicotine therapy," Alimentary Pharmacology and Therapeutics, vol. 36, no. 11-12, pp. 997-1008, 2012.

[49] S. Verschuere, R. De Smet, L. Allais, and C. A. Cuvelier, "The effect of smoking on intestinal inflammation: what can be learned from animal models?" Journal of Crohn's and Colitis, vol. 6, no. 1, pp. 1-12, 2012.

[50] K. Kawashima, A. Nomura, T. Makino, K.-I. Saito, and Y. Kano, "Pharmacological properties of traditional medicine (XXIX): effect of hange-shashin-to and the combinations of its herbal constituents on rat experimental colitis," Biological \& Pharmaceutical Bulletin, vol. 27, no. 10, pp. 1599-1603, 2004.

[51] J.-G. Chen and H.-Z. Deng, "Effects of total base of Sophora alopecuroides on expression of SOD, MDA, NO, MPO in rats with experimental colitis," Zhongguo Zhong Yao Za Zhi, vol. 31, no. 4, pp. 323-325, 2006.

[52] Y. Zhou, H. Wang, L. Liang, W.-C. Zhao, Y. Chen, and H.Z. Deng, "Total alkaloids of Sophora alopecuroides increases the expression of $\mathrm{CD}^{+} \mathrm{CD} 25^{+}$tregs and IL-10 in rats with experimental colitis," American Journal of Chinese Medicine, vol. 38, no. 2, pp. 265-277, 2010.

[53] X. Wang, B. Jiang, L. Li, H. Yao, and H. Deng, "Effects of total alkaloid of Sophora alopecuroides on serum IL-1 $\beta$ and IL4 expression in mice with acute ulcerative colitis," Zhongguo Zhongyao Zazhi, vol. 35, no. 9, pp. 1177-1180, 2010.

[54] W.-C. Zhao, L.-J. Song, and H.-Z. Deng, "Protective effect of total alkaloids of sophora alopecuroides on dextran sulfate sodium-induced chronic colitis," Chinese Journal of Integrative Medicine, vol. 17, no. 8, pp. 616-624, 2011.

[55] L. Liu, S. Yuan, Y. Sun et al., "The possible mechanisms of Fructus Mume pill in the treatment of colitis induced by 2,4,6trinitrobenzene sulfonic acid in rats," Journal of Ethnopharmacology, vol. 126, no. 3, pp. 557-564, 2009.

[56] M. Zhang, Y. Long, Y. Sun et al., "Evidence for the complementary and synergistic effects of the three-alkaloid combination regimen containing berberine, hypaconitine and skimmianine on the ulcerative colitis rats induced by trinitrobenzenesulfonic acid," European Journal of Pharmacology, vol. 651, no. 1-3, pp. 187-196, 2011. 
[57] E. Vrublova, J. Vostalova, J. Ehrmann et al., "The phytogenic feed additive Sangrovit modulates dextran sulfate sodiuminduced colitis in rats," Veterinarni Medicina, vol. 55, no. 12, pp. 610-618, 2010.

[58] V. Iablokov, B. C. Sydora, R. Foshaug et al., "Naturally occurring glycoalkaloids in potatoes aggravate intestinal inflammation in two mouse models of inflammatory bowel disease," Digestive Diseases and Sciences, vol. 55, no. 11, pp. 3078-3085, 2010.

[59] S. A. Nirmal, J. M. Ingale, S. R. Pattan, and S. B. Bhawar, "Amaranthus roxburghianus root extract in combination with piperine as a potential treatment of ulcerative colitis in mice," Journal of Integrative Medicine, vol. 11, no. 3, pp. 206-212, 2013.

[60] N. Bribi, F. Algieri, A. Rodriguez-Nogales et al., "Intestinal antiinflammatory effects of total alkaloid extract from Fumaria capreolata in the DNBS model of mice colitis and intestinal epithelial CMT93 cells," Phytomedicine, vol. 23, no. 9, pp. 901913, 2016.

[61] Z.-H. Zhang, H.-J. Zhang, A.-J. Deng et al., "Synthesis and structure-activity relationships of quaternary coptisine derivatives as potential anti-ulcerative colitis agents," Journal of Medicinal Chemistry, vol. 58, no. 18, pp. 7557-7571, 2015.

[62] P. Wangchuk, S. Navarro, C. Shepherd, P. A. Keller, S. G. Pyne, and A. Loukas, "Diterpenoid alkaloids of Aconitum laciniatum and mitigation of inflammation by $14-\mathrm{O}$-acetylneoline in a murine model of ulcerative colitis," Scientific Reports, vol. 5, article 12845, 2015.

[63] H. Zhou and S. Mineshita, "The effect of berberine chloride on experimental colitis in rats in vivo and in vitro," Journal of Pharmacology and Experimental Therapeutics, vol. 294, no. 3, pp. 822-829, 2000.

[64] I.-A. Lee, Y.-J. Hyun, and D.-H. Kim, "Berberine ameliorates TNBS-induced colitis by inhibiting lipid peroxidation, enterobacterial growth and NF- $\kappa$ B activation," European Journal of Pharmacology, vol. 648, no. 1-3, pp. 162-170, 2010.

[65] M. Minaiyan, A. Ghannadi, P. Mahzouni, and E. JaffariShirazi, "Comparative study of Berberis vulgaris fruit extract and berberine chloride effects on acetic acid-induced colitis in rats," Iranian Journal of Pharmaceutical Research, vol. 10, no. 1, pp. 97-104, 2011.

[66] F. Yan, L. Wang, Y. Shi et al., "Berberine promotes recovery of colitis and inhibits inflammatory responses in colonic macrophages and epithelial cells in DSS-treated mice," American Journal of Physiology-Gastrointestinal and Liver Physiology, vol. 302, no. 5, pp. G504-G514, 2012.

[67] T. Hong, Z. Yang, C.-F. Lv, and Y. Zhang, "Suppressive effect of berberine on experimental dextran sulfate sodium-induced colitis," Immunopharmacology and Immunotoxicology, vol. 34, no. 3, pp. 391-397, 2012.

[68] M. Kawano, R. Takagi, A. Kaneko, and S. Matsushita, "Berberine is a dopamine D1- and D2-like receptor antagonist and ameliorates experimentally induced colitis by suppressing innate and adaptive immune responses," Journal of Neuroimmunology, vol. 289, pp. 43-55, 2015.

[69] Y. H. Li, H. T. Xiao, D. D. Hu et al., "Berberine ameliorates chronic relapsing dextran sulfate sodium-induced colitis in C57BL/6 mice by suppressing Th17 responses," Pharmacological Research, vol. 110, pp. 227-239, 2016.

[70] A. K. Pandurangan, N. Mohebali, M. Hasanpourghadi, C. Y. Looi, M. R. Mustafa, and N. Mohd Esa, "Boldine suppresses dextran sulfate sodium-induced mouse experimental colitis: NF- $\kappa$ B and IL-6/STAT3 as potential targets," BioFactors, vol. 42, no. 3, pp. 247-258, 2016.
[71] I.-A. Lee, D. Low, A. Kamba, V. Llado, and E. Mizoguchi, “Oral caffeine administration ameliorates acute colitis by suppressing chitinase 3-like 1 expression in intestinal epithelial cells," Journal of Gastroenterology, vol. 49, no. 8, pp. 1206-1216, 2014.

[72] X. Niu, H. Zhang, W. Li et al., "Protective effect of cavidine on acetic acid-induced murine colitis via regulating antioxidant, cytokine profile and NF- $\kappa$ B signal transduction pathways," Chemico-Biological Interactions, vol. 239, pp. 34-45, 2015.

[73] K. Kaur, R. K. Sodhi, A. Katyal et al., "Wheat germ agglutinin anchored chitosan microspheres of reduced brominated derivative of noscapine ameliorated acute inflammation in experimental colitis," Colloids and Surfaces B: Biointerfaces, vol. 132, pp. 225-235, 2015.

[74] X.-F. Wu, M.-J. Fei, R.-G. Shu, R.-X. Tan, and Q. Xu, "Fumigaclavine $\mathrm{C}$, an fungal metabolite, improves experimental colitis in mice via downregulating Thl cytokine production and matrix metalloproteinase activity," International Immunopharmacology, vol. 5, no. 10, pp. 1543-1553, 2005.

[75] E. A. Rabelo Socca, A. Luiz-Ferreira, F. M. De Faria et al., "Inhibition of tumor necrosis factor-alpha and cyclooxigenase2 by Isatin: a molecular mechanism of protection against TNBSinduced colitis in rats," Chemico-Biological Interactions, vol. 209, no. 1, pp. 48-55, 2014.

[76] H. Cheng, B. Xia, L. Zhang et al., "Matrine improves 2,4,6trinitrobenzene sulfonic acid-induced colitis in mice," Pharmacological Research, vol. 53, no. 3, pp. 202-208, 2006.

[77] J.-F. Liu, M. Shao, D.-W. Zhai, K. Liu, and L.-J. Wu, "Protective effect of 4-methoxy-5-hydroxycanthin-6-one, a natural alkaloid, on dextran sulfate sodium-induced rat colitis," Planta Medica, vol. 75, no. 2, pp. 142-145, 2009.

[78] T. Wen, Y. Li, M. Wu et al., "A novel tylophorine analog NK007 ameliorates colitis through inhibition of innate immune response," International Immunopharmacology, vol. 14, no. 4, pp. 487-494, 2012.

[79] P. Zheng, F.-L. Niu, W.-Z. Liu, Y. Shi, and L.-G. Lu, "Antiinflammatory mechanism of oxymatrine in dextran sulfate sodium-induced colitis of rats," World Journal of Gastroenterology, vol. 11, no. 31, pp. 4912-4915, 2005.

[80] H. Fan, Y. Liao, Q. Tang et al., "Role of $\beta 2$-adrenoceptor- $\beta$ arrestin2-nuclear factor- $\kappa \mathrm{B}$ signal transduction pathway and intervention effects of oxymatrine in ulcerative colitis," Chinese Journal of Integrative Medicine, vol. 18, no. 7, pp. 514-521, 2012.

[81] Y. Liao, H. Fan, and X.-Y. Chen, "Pathogenetic mechanism of beta-arrestinl in experimental colitis of rats and intervention effects of oxymatrine," Chinese Journal of Integrated Traditional and Western Medicine, vol. 30, no. 10, pp. 1067-1072, 2010.

[82] H. Fan, R. Chen, L. Shen et al., "Oxymatrine improves TNBSinduced colitis in rats by inhibiting the expression of NF- $\kappa \mathrm{B}$ p65," Journal of Huazhong University of Science and Technology: Medical Science, vol. 28, no. 4, pp. 415-420, 2008.

[83] J. R. Guzman, J. S. Koo, J. R. Goldsmith, M. Mühlbauer, A. Narula, and C. Jobin, "Oxymatrine prevents NF- $\kappa$ B nuclear translocation and ameliorates acute intestinal inflammation," Scientific Reports, vol. 3, article 1629, 2013.

[84] N. R. Harris, R. D. Specian, P. R. Carter, and G. A. Morgan, "Contrasting effects of pseudoephedrine and papaverine in dextran sodium sulfate-induced colitis," Inflammatory Bowel Diseases, vol. 14, no. 3, pp. 318-323, 2008.

[85] D. Hu, Y. Wang, Z. Chen et al., "The protective effect of piperine on dextran sulfate sodium induced inflammatory bowel disease and its relation with pregnane X receptor activation," Journal of Ethnopharmacology, vol. 169, article no. 9449, pp. 109-123, 2015. 
[86] R. A. Gupta, M. N. Motiwala, N. G. Dumore, K. R. Danao, and A. B. Ganjare, "Effect of piperine on inhibition of FFA induced TLR4 mediated inflammation and amelioration of acetic acid induced ulcerative colitis in mice," Journal of Ethnopharmacology, vol. 164, pp. 239-246, 2015.

[87] X. Niu, T. Fan, W. Li, H. Huang, Y. Zhang, and W. Xing, "Protective effect of sanguinarine against acetic acid-induced ulcerative colitis in mice," Toxicology and Applied Pharmacology, vol. 267, no. 3, pp. 256-265, 2013.

[88] H. Cheng, B. Xia, Q. Guo et al., "Sinomenine attenuates 2, 4, 6-trinitrobenzene sulfonic acid-induced colitis in mice," International Immunopharmacology, vol. 7, no. 5, pp. 604-611, 2007.

[89] Q. Yu, S. Zhu, R. Zhou et al., "Effects of sinomenine on the expression of microRNA-155 in 2,4,6-trinitrobenzenesulfonic acid-induced colitis in mice," PLoS ONE, vol. 8, no. 9, Article ID e73757, 2013.

[90] X.-J. Wang, H.-Z. Deng, B. Jiang, and H. Yao, "The natural plant product sophocarpine ameliorates dextran sodium sulfate-induced colitis in mice by regulating cytokine balance," International Journal of Colorectal Disease, vol. 27, no. 5, pp. 575581, 2012.

[91] W.-C. Zhao, L.-J. Song, and H.-Z. Deng, "Effect of sophoridine on dextran sulfate sodium-induced colitis in C57BL/6 mice," Journal of Asian Natural Products Research, vol. 12, no. 11, pp. 925-933, 2010.

[92] D. K. Zhang, L. N. Cheng, X. L. Huang, W. Shi, J. Y. Xiang, and H. T. Gan, "Tetrandrine ameliorates dextran-sulfate-sodiuminduced colitis in mice through inhibition of nuclear factor $-\kappa \mathrm{B}$ activation," International Journal of Colorectal Disease, vol. 24, no. 1, pp. 5-12, 2009.

[93] I. G. Agafonova and T. V. Moskovkina, "Studies on Antiinflammatory action of tryptanthrin, using a model of DSSInduced colitis of mice and magnetic resonance imaging," Applied Magnetic Resonance, vol. 46, no. 7, pp. 781-791, 2015.

[94] X. Meng, Y. Zhang, Z. Jia et al., "A novel tylophorine analog W-8 up-regulates forkhead boxP3 expression and ameliorates murine colitis," Journal of Leukocyte Biology, vol. 93, no. 1, pp. 83-93, 2013.

[95] N. Mokhber-Dezfuli, S. Saeidnia, A. Gohari, and M. KurepazMahmoodabadi, "Phytochemistry and pharmacology of berberis species," Pharmacognosy Reviews, vol. 8, no. 15, pp. $8-15,2014$.

[96] M. Tillhon, L. M. Guamán Ortiz, P. Lombardi, and A. I. Scovassi, "Berberine: new perspectives for old remedies," Biochemical Pharmacology, vol. 84, no. 10, pp. 1260-1267, 2012.

[97] R. Gautam and S. M. Jachak, "Recent developments in antiinflammatory natural products," Medicinal Research Reviews, vol. 29, no. 5, pp. 767-820, 2009.

[98] L. Gu, N. Li, Q. Li et al., "The effect of berberine in vitro on tight junctions in human Caco-2 intestinal epithelial cells," Fitoterapia, vol. 80, no. 4, pp. 241-248, 2009.

[99] K. M. DiGuilio, C. M. Mercogliano, J. Born et al., "Sieving characteristics of cytokine- and peroxide-induced epithelial barrier leak: inhibition by berberine," World Journal of Gastrointestinal Pathophysiology, vol. 7, no. 2, pp. 223-234, 2016.

[100] J. Zhao, S. Yu, L. Tong et al., "Oxymatrine attenuates intestinal ischemia/reperfusion injury in rats," Surgery Today, vol. 38, no. 10, pp. 931-937, 2008.

[101] T. Gao, J. Hao, Z. Wiesenfeld-Hallin, D.-Q. Wang, and X.-J. Xu, "Analgesic effect of sinomenine in rodents after inflammation and nerve injury," European Journal of Pharmacology, vol. 721, no. 1-3, pp. 5-11, 2013.

[102] J.-X. Zhang, Z.-R. Yang, D.-D. Wu et al., "Suppressive effect of sinomenine combined with 5-fluorouracil on colon carcinoma cell growth," Asian Pacific Journal of Cancer Prevention, vol. 15, no. 16, pp. 6737-6743, 2014.

[103] Z. Liu, Z.-J. Duan, J.-Y. Chang et al., "Sinomenine sensitizes multidrug-resistant colon cancer cells (Caco-2) to doxorubicin by downregulation of MDR-1 expression," PLoS ONE, vol. 9, no. 6, Article ID e98560, 2014.

[104] Q. Wang and X.-K. Li, "Immunosuppressive and anti-inflammatory activities of sinomenine," International Immunopharmacology, vol. 11, no. 3, pp. 373-376, 2011.

[105] Q. Li, W. Zhai, Q. Jiang et al., "Curcumin-piperine mixtures in self-microemulsifying drug delivery system for ulcerative colitis therapy," International Journal of Pharmaceutics, vol. 490, no. 12, pp. 22-31, 2015.

[106] V. Yadav, F. Varum, R. Bravo, E. Furrer, D. Bojic, and A. W. Basit, "Inflammatory bowel disease: exploring gut pathophysiology for novel therapeutic targets," Translational Research, vol. 176, pp. 38-68, 2016.

[107] B. Ungar and U. Kopylov, "Advances in the development of new biologics in inflammatory bowel disease," Annals of Gastroenterology, vol. 29, no. 3, pp. 1-6, 2016.

[108] P. S. Dulai and W. J. Sandborn, "Next-generation therapeutics for inflammatory bowel disease," Current Gastroenterology Reports, vol. 18, no. 9, article 51, 2016.

[109] M. Iqbal, R. Verpoorte, H. A. A. J. Korthout, and N. R. Mustafa, "Phytochemicals as a potential source for TNF- $\alpha$ inhibitors," Phytochemistry Reviews, vol. 12, no. 1, pp. 65-93, 2013.

[110] M. Sałaga, H. Zatorski, M. Sobczak, C. Chen, and J. Fichna, "Chinese herbal medicines in the treatment of IBD and colorectal cancer: a review," Current treatment options in oncology, vol. 15, no. 3, pp. 405-420, 2014.

[111] T. Debnath, D. H. Kim, and B. O. Lim, "Natural products as a source of anti-inflammatory agents associated with inflammatory bowel disease," Molecules, vol. 18, no. 6, pp. 7253-7270, 2013.

[112] C. Chen, C. Tao, Z. Liu et al., "A randomized clinical trial of berberine hydrochloride in patients with diarrheapredominant irritable bowel syndrome," Phytotherapy Research, vol. 29, no. 11, pp. 1822-1827, 2015.

[113] H.-M. Yan, M.-F. Xia, Y. Wang et al., "Efficacy of berberine in patients with non-alcoholic fatty liver disease," PLOS ONE, vol. 10, no. 8, Article ID e0134172, 2015.

[114] S. Meng, L.-S. Wang, Z.-Q. Huang et al., "Berberine ameliorates inflammation in patients with acute coronary syndrome following percutaneous coronary intervention," Clinical and Experimental Pharmacology and Physiology, vol. 39, no. 5, pp. 406-411, 2012.

[115] Y. Li, M. Zhang, H. Xiao et al., "Addition of berberine to 5aminosalicylic acid for treatment of dextran sulfate sodiuminduced chronic colitis in C57BL/6 mice," PLOS ONE, vol. 10, no. 12, Article ID e0144101, 2015.

[116] M. M. Abdel-Daim, S. M. Aly, K. Abo-el-Sooud, M. Giorgi, and S. Ursoniu, "Role of natural products in ameliorating drugs and chemicals toxicity," Evidence-Based Complementary and Alternative Medicine, vol. 2016, Article ID 7879406, 2 pages, 2016. 


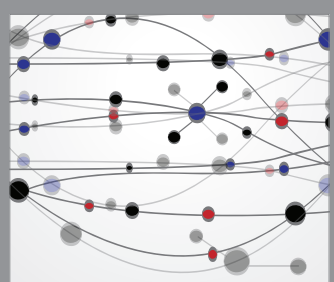

The Scientific World Journal
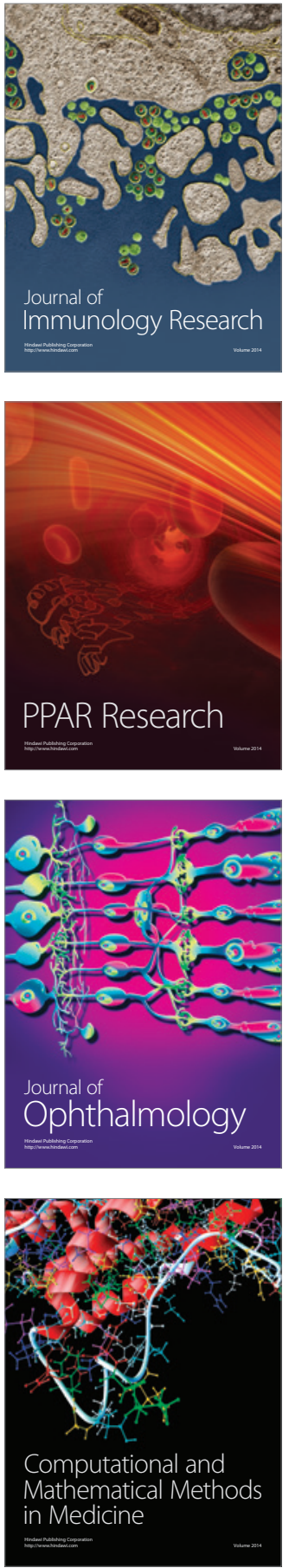

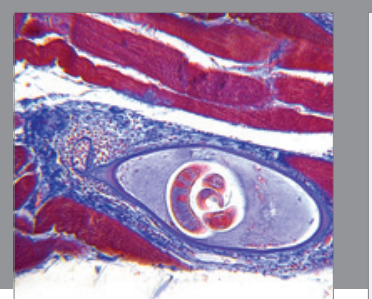

Gastroenterology Research and Practice
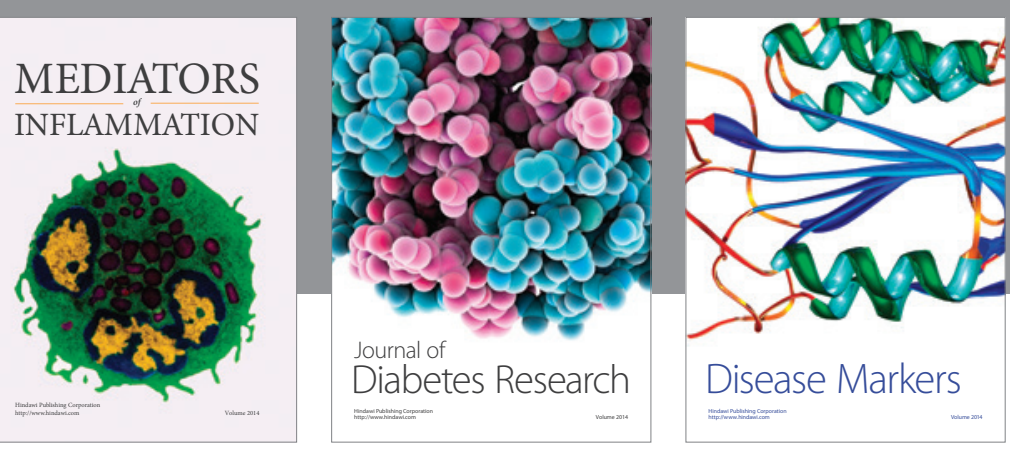

Disease Markers

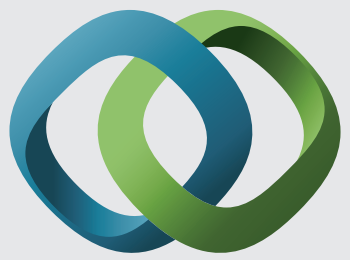

\section{Hindawi}

Submit your manuscripts at

https://www.hindawi.com
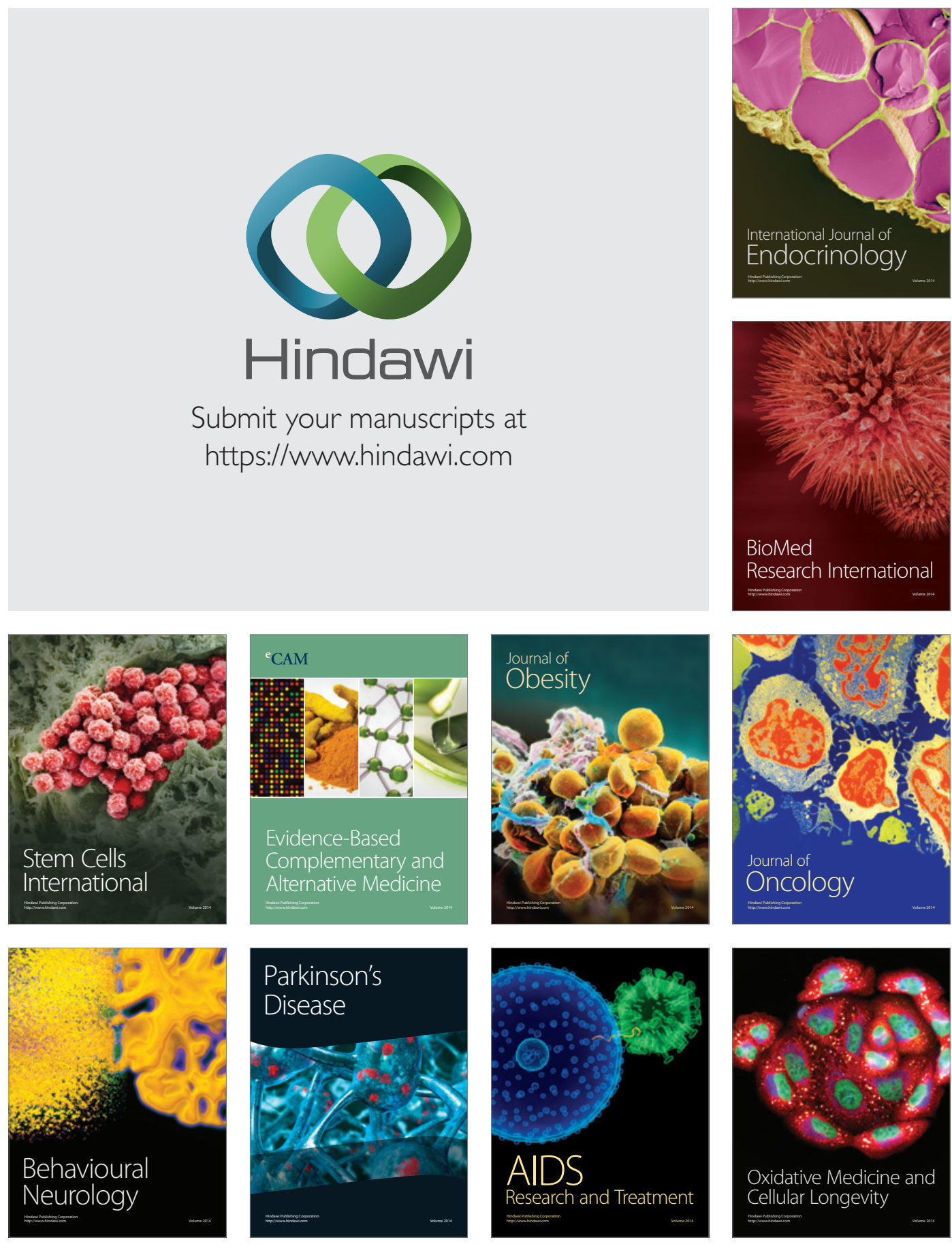